\title{
The Proteasomal Deubiquitinating Enzyme PSMD14 Regulates Macroautophagy by Controlling Golgi-to-ER Retrograde Transport
}

\author{
Hianara A Bustamante ${ }^{1,{ }^{\dagger}}$, Karina Cereceda ${ }^{2}$, Alexis E González ${ }^{1, \ddagger}$, Guillermo E Valenzuela ${ }^{3,4}{ }^{\circledR}$, \\ Yorka Cheuquemilla ${ }^{4}$, Sergio Hernández ${ }^{2}$, Eloisa Arias-Muñoz ${ }^{2}$, Cristóbal Cerda-Troncoso ${ }^{2}$, \\ Susanne Bandau ${ }^{5}$, Andrea Soza ${ }^{2}(D)$, Gudrun Kausel ${ }^{3}{ }^{-}$, Bredford Kerr ${ }^{2}$, Gonzalo A Mardones ${ }^{1,6}$, \\ Jorge Cancino ${ }^{2}$, Ronald T Hay ${ }^{5}$, Alejandro Rojas-Fernandez ${ }^{4,5, *}$ and Patricia V Burgos ${ }^{2,7, *}$ \\ 1 Instituto de Fisiología, Facultad de Medicina, Universidad Austral de Chile, Valdivia 5110566, Chile; \\ lahianara@gmail.com (H.A.B.); alexisgonzalez003@gmail.com (A.E.G.); gonzalo.mardones@uach.cl (G.A.M.) \\ 2 Centro de Biología Celular y Biomedicina (CEBICEM), Facultad de Medicina y Ciencia, \\ Universidad San Sebastián, Lota 2465, Santiago 7510157, Chile; cereceda.karina@gmail.com (K.C.); \\ felipehg1991@gmail.com (S.H.); eloisa.arias.m@gmail.com (E.A.-M.); cct.troncoso@gmail.com (C.C.-T.); \\ andrea.soza@uss.cl (A.S.); bredford.kerr@uss.cl (B.K.); jorge.cancino@uss.cl (J.C.) \\ 3 Instituto de Bioquímica y Microbiología, Facultad de Ciencias, Universidad Austral de Chile, \\ Valdivia 5110566, Chile; guillervn7@gmail.com (G.E.V.); gkausel@gmail.com (G.K.) \\ 4 Instituto de Medicina \& Centro Interdisciplinario de Estudios del Sistema Nervioso (CISNe), \\ Universidad Austral de Chile, Valdivia 5110566, Chile; ycheuquemilla@gmail.com \\ 5 Centre for Gene Regulation and Expression, College of Life Sciences, University of Dundee, DD1 4HN, \\ Dundee DD1 4HN UK; s.bandau@dundee.ac.uk (S.B.); R.T.Hay@dundee.ac.uk (R.T.H.) \\ 6 Centro Interdisciplinario de Estudios del Sistema Nervioso (CISNe), Universidad Austral de Chile, \\ Valdivia 5110566, Chile \\ 7 Centro de Envejecimiento y Regeneración (CARE-UC), Facultad de Ciencias Biológicas, \\ Pontificia Universidad Católica de Chile, Santiago 83330023, Chile \\ * Correspondence: alejandro.rojas@uach.cl (A.R.-F.); patricia.burgos@uss.cl (P.V.B.); \\ Tel.: +56-63-2444315 (A.R.-F.); +56-2-22606309 (P.V.B.) \\ † Current address: Instituto de Microbiología Clínica, Facultad de Medicina, Universidad Austral de Chile, \\ Valdivia 5110566, Chile. \\ $\ddagger$ Current address: Institute of Biochemistry II, School of Medicine, Goethe University Frankfurt, \\ Theoder-Stern-Kai 7, 60590 Frankfurt am Main, Germany.
}

Received: 25 February 2020; Accepted: 19 March 2020; Published: 23 March 2020

\begin{abstract}
Ubiquitination regulates several biological processes, however the role of specific members of the ubiquitinome on intracellular membrane trafficking is not yet fully understood. Here, we search for ubiquitin-related genes implicated in protein membrane trafficking performing a High-Content siRNA Screening including 1187 genes of the human "ubiquitinome" using amyloid precursor protein (APP) as a reporter. We identified the deubiquitinating enzyme PSMD14, a subunit of the 19S regulatory particle of the proteasome, specific for $\mathrm{K} 63-\mathrm{Ub}$ chains in cells, as a novel regulator of Golgi-to-endoplasmic reticulum (ER) retrograde transport. Silencing or pharmacological inhibition of PSMD14 with Capzimin (CZM) caused a robust increase in APP levels at the Golgi apparatus and the swelling of this organelle. We showed that this phenotype is the result of rapid inhibition of Golgi-to-ER retrograde transport, a pathway implicated in the early steps of the autophagosomal formation. Indeed, we observed that inhibition of PSMD14 with CZM acts as a potent blocker of macroautophagy by a mechanism related to the retention of Atg9A and Rab1A at the Golgi apparatus. As pharmacological inhibition of the proteolytic core of the $20 S$ proteasome did not recapitulate these effects, we concluded that PSMD14, and the K63-Ub chains, act as a crucial regulatory factor for macroautophagy by controlling Golgi-to-ER retrograde transport.
\end{abstract}

Keywords: PSMD14; ubiquitin; retrograde; trafficking; APP 


\section{Introduction}

Several post-translational modifications (PTMs) contribute to membrane transport [1,2]. Among these, ubiquitination acts as a relevant player in protein membrane trafficking [3-5] participating as an important protein localization signal [3,6-8]. However, to date, most studies have focused on its role in endocytosis, particularly in the inclusion of cargoes in intraluminal vesicles (ILVs) of multivesicular bodies (MVBs) [9-11] such as cell-surface receptors [12]. Ubiquitination is a regulated post-translational modification that conjugates ubiquitin $(\mathrm{Ub})$ to lysine $(\mathrm{K})$ residues and is involved in many cellular pathways including the degradation of target proteins through the proteasomes and autophagy $[13,14]$. Ubiquitin modification is a cascade of reactions catalyzed by three classes of enzymes (E1, E2 and E3). An ATP-dependent E1 activating enzymes first forms a covalent intermediate with ubiquitin, followed by the transfer of $\mathrm{Ub}$ to $\mathrm{E} 2$ conjugating enzymes and finally the covalent attachment of $\mathrm{Ub}$ to a $\mathrm{K}$ residue in the target protein by E3 Ub ligases [15]. Ubiquitination is a reversible reaction, with specific deubiquitinating enzymes (DUBs) that catalyze the removal of Ub-moieties for their recycling. DUBs serve to counterbalance ubiquitination reactions within the cell, thus dynamically contributing to the regulation of various cellular processes, such as endosomal sorting [11,16-18].

$\mathrm{Ub}$ increases proteome complexity, providing an additional surface for protein-protein interactions and functional regulation $[19,20]$. Ub-modified proteins and $\mathrm{Ub}$ chains are recognized by several $\mathrm{Ub}$ receptors including a family of specialized proteins carrying $\mathrm{Ub}$ binding domains (UBDs). To date, over 20 UBD families have been identified and characterized in mammals participating in the recognition of $\mathrm{Ub}$ monomers or $\mathrm{Ub}$ chains on specific substrates $[4,14,21]$. Together, the $\mathrm{Ub}$ network offers a variety of choices to modulate cellular processes including protein membrane trafficking. However, the contribution of the ubiquitinome regarding its impact on intracellular membrane trafficking is not yet fully understood.

To investigate the contribution of most of the members of the ubiquitinome in protein membrane trafficking, we performed high-content siRNA screening (HCS) including 1187 genes of the human "ubiquitinome". For this screening we used a stable cell line expressing amyloid precursor protein (APP) fused to the enhanced green fluorescent protein (EGFP). APP was the protein selected as target because it traffics dynamically through the secretory and endocytic pathways containing specific sorting signal motifs [22-24] and specific lysine residues targets of ubiquitination [25-28]. We thus identified the deubiquitinating (DUB) enzyme PSMD14, a subunit of the 195 regulatory particle (RP) of the proteasome, as a crucial player of Golgi-to-Endoplasmic reticulum (ER) retrograde transport. The DUB enzyme PSMD14 has been shown to be specific for K63-Ub chains in cells [29]. Here, we found that the inhibition of its activity blocks Golgi-to-ER retrograde transport, causing the swelling of the Golgi apparatus. We also found that PSMD14 inhibition acts as a potent blocker of macroautophagy as a result of its negative impact in Golgi-to-ER retrograde transport. Inhibition of the proteolytic core of the $20 \mathrm{~S}$ proteasome by MG132 did not recapitulate these effects, indicating that the 19S RP plays a role in macroautophagy by controlling membrane trafficking at the early secretory pathway.

\section{Materials and Methods}

\subsection{Chemical Reagents}

Earle's balanced salt solution (EBSS) and the cocktail of protease inhibitors were purchased from Sigma-Aldrich (St. Louis, MO, USA). MG132 was purchased from Millipore (Burlington, MA, USA). Torin-1 was purchased from Tocris Bioscience (Bristol, UK). Dr. Raymond Deshaies from California Institute of Technology (Caltech, CA, USA) and Dr. Yuyong Ma from The University of California, CA, USA kindly donated Capzimin (CZM). 


\subsection{Antibodies}

The following monoclonal antibodies were used: mouse anti-ubiquitin clone P4D1 (Cytoskeleton, Inc, Denver, CO, USA), mouse anti- $\beta$-actin clone BA3R (Thermo Fisher Scientific, Waltham, MA, USA), rabbit anti-RAB1A clone D3X9S, mouse anti-GM130 clone 35/GM130, rabbit anti-PSMD14 clone D18C7 (Cell Signaling Technology, Danvers, MA, USA) and rabbit anti-ATG9A clone EPR2450(2) (Abcam, Cambridge, UK). We used the following polyclonal antibodies: rabbit anti-ubiquitin (cat: Z0458, Dako, Carpintería, CA, USA), rabbit anti-giantin (cat: AB24586, Abcam, Cambridge, UK), rabbit anti-LC3 (cat: 2775S, Cell Signaling Technology, Danvers, MA, USA), rabbit anti-APP CT695 (cat: 51-2700, Thermo Fisher Scientific). Horseradish peroxidase-conjugated secondary antibodies were purchased from Jackson ImmunoResearch Laboratories (West Grove, PA, USA), and DAPI probe, Alexa and Dylight fluorophore-conjugated secondary antibodies were purchased from Thermo Fisher Scientific.

\subsection{Cell Culture}

H4 ATCC ${ }^{\circledR}$ HTB-148 ${ }^{\text {TM }}$ Homo sapiens brain neuroglioma cells, referred to here as H4 human neuroglioma cells and HeLa ATCC ${ }^{\circledR}$ CCL-2 ${ }^{\mathrm{TM}}$ cells were obtained from the American Type Culture Collection (Manassas, VA, USA). Cell lines were cultured in Dulbecco's modified Eagle's medium (DMEM; Thermo Fisher Scientific) supplemented with 10\% (vol/vol) heat-inactivated fetal bovine serum (FBS; Thermo Fisher Scientific), and penicillin/streptomycin (Thermo Fisher Scientific), in a 5\% $\mathrm{CO}_{2}$ atmosphere at $37^{\circ} \mathrm{C}$. The generation of the $\mathrm{H} 4$ stable cell line expressing hemagglutinin-tagged $\mathrm{APP}_{695}-\mathrm{F} / \mathrm{P}-\mathrm{D} / \mathrm{A}-\mathrm{EGFP}$ (APP-EGFP) and the HeLa stable cell line expressing KDELR1-GFP were previously reported [30-32]. Stably transfected cells were maintained in culture medium supplemented with $100 \mu \mathrm{g} / \mathrm{mL}$ Cells were grown to sub confluence and then treated with drugs or transfected with siRNAs for further western blot and immunofluorescence analyses. Nutrient starvation assays were performed in the presence of EBSS. Assays to detect Mycoplasm were performed periodically.

\subsection{High Content siRNA Transfection and Imaging}

The primary siRNA screen for levels of APP-EGFP was performed in duplicates with our custom-assembled "Ubiquitinome" siRNA library, which consists of 1187 SMARTpools siRNAs targeting all known and assumed components of the ubiquitin and ubiquitin-like systems in 96-well format, as previously reported [33,34]. The H4 cells stably expressing APP-EGFP were reverse transfected [33,34] in $\mu$ Clear bottom 96-well plates (Greiner Bio-One, Kremsmünster, Austria) with ON-TARGETplus SMARTpools siRNAs (GE Dharmacon, Lafayette, CO, USA). Additionally, ON-TARGETplus Non-targeting pool (NT siRNA) was used together with untransfected cells (Mock) as neutral control; siRNA against GFP (GFP siRNA) was used as a positive control for APP downregulation. Briefly, $10 \mu \mathrm{L}$ siRNA $(200 \mathrm{nM})$ were stamped from 96-well plates of the library on to $\mu$ Clear bottom 96 well plates. Thereafter, $10 \mu \mathrm{L}$ of Opti-MEM I Reduced Serum Medium (Thermo Fisher Scientific) containing Lipofectamine RNAiMAX transfection reagent (Thermo Fisher Scientific) was added to the siRNA (dilution 1:50). Plates were shaken at $900 \mathrm{rpm}$ for $1 \mathrm{~min}$ followed by incubation for $20 \mathrm{~min}$ at room temperature. During this incubation, cells were resuspended in DMEM supplemented with $10 \%$ $(v / v)$ FBS and $1 \times$ Normocin (InvivoGen, San Diego, CA, USA) and 6000 cells were dispensed onto each well loaded with medium for a final siRNA concentration of $20 \mathrm{nM}$. Plates were incubated for $72 \mathrm{~h}$ and further prepared for high content measurement.

After transfection, cells were stained using $100 \mu \mathrm{L}$ of reagent per step, dispensed by the automated reagent dispenser XPP-721 (fluidX, Manchester, UK), according to the following protocol: two washes in phosphate buffered saline (PBS); fixation in 3.7\% (v/v) paraformaldehyde for $10 \mathrm{~min}$; one wash in PBS; incubation with $0.2 \%(v / v)$ Triton X-100 in PBS for 10 min; two washes in PBS; incubation with $0.1 \mu \mathrm{g} / \mathrm{mL}$ DAPI for $5 \mathrm{~min}$; two washes with PBS. Finally, $100 \mu \mathrm{L}$ of PBS was left in each well. Images were acquired and analyzed using the automated microscope IN Cell 2000 Analyzer (GE Healthcare, Little Chalfont, UK). Images of six randomized fields per well with $\sim 600$ cells each were acquired, and further analyzed the total fluorescence intensity in $n>2000$ cells per condition. A secondary siRNA 
screening was performed in triplicate targeting the 35 most responsive hits, using each single siRNA duplex derived from the SMARTpools used in the primary siRNA screening.

\section{5. siRNA Transfection for the siRNA Screening Validation Stage}

Four single siRNA sequences targeting human PSMD14 (Accession number: NM_005805), derived from the ON-TARGETplus SMARTpool used in the siRNA Screening (Figure S1) were purchased from GE Dharmacon (Lafayette, CO, USA). siRNA transfections were carried out in $60 \mathrm{~mm}$ tissue culture plates using the Lipofectamine RNAiMax transfection reagent (Thermo Fisher Scientific) according to the manufacturer's protocol, and after $72 \mathrm{~h}$ cells were collected for further analysis.

\subsection{RNA isolation and RT-qPCR Analysis}

Total RNA extraction from $\mathrm{H} 4$ cells was carried out using the E.Z.N.A. ${ }^{\circledR}$ Total RNA Kit I (Omega Biotek, Norcross, GA, USA), and either purity (260/280 nm ratio and 260/230 nm ratio) or quantity (260 nm absorbance) were determined by spectrophotometry using NanoVue Spectrophotometer (GE Healthcare). The cDNA synthesis was performed from $2.5 \mu \mathrm{g}$ of total RNA and oligo-dT and MMLV reverse transcriptase (Promega, Madison, WI, USA) according to supplier instructions. Specific primer pairs for tbp (NM_003194), psmd14 (NM_005805) and app (NM_000484) human genes were designed for quantitative reverse transcription PCR on cDNA template (RT-qPCR) (Figure S2). First, the specificity of amplicons was verified by cloning and sequencing, including tbp (223 bp), psmd14 (150 bp) and app (247 bp). mRNA levels were quantified in cDNA by qPCR with GoTaq qPCR Master Mix (Promega) according to supplier's instructions in a M $\times 3000$ Real-Time Thermocycler (Stratagene, San Diego, CA, USA). In a 40 -cycle PCR reaction, each cycle consisted of $20 \mathrm{~s}$ at $94{ }^{\circ} \mathrm{C}, 15 \mathrm{~s}$ at $55^{\circ} \mathrm{C}$ and $15 \mathrm{~s}$ at $72{ }^{\circ} \mathrm{C}$, followed by a final heating at $95{ }^{\circ} \mathrm{C}$, revealing melting curves that confirmed single amplification products. All analyses were performed in triplicate. The expression level of each gene was normalized to tbp expression as reference gene using exon-spanning primers to control for genomic DNA contamination since no DNAse treatment of total RNA was included. RT-qPCR assays were analyzed with 2(- $\Delta \Delta \mathrm{Ct}$ ) method [35] via MxPro software (Stratagene) and expressed as relative quantity to normalizer [36].

\subsection{Preparation of Protein Extracts, Electrophoresis, SDS-PAGE and Western Blot Analysis}

Cells were washed in ice-cold phosphate buffered saline (PBS) and lysed at $4{ }^{\circ} \mathrm{C}$ in lysis buffer (50 mM Tris- $\mathrm{HCl}$ pH 7.4, $150 \mathrm{mM} \mathrm{NaCl}, 1 \mathrm{mM}$ EDTA, $1 \%(v / v)$ Triton X-100) supplemented with a cocktail of protease inhibitors (Sigma-Aldrich). All lysates were cleared by centrifugation at $16,000 \times g$ for $20 \mathrm{~min}$ at $4{ }^{\circ} \mathrm{C}$, and protein concentration was determined with a protein assay dye reagent (Bio-Rad Laboratories, Hercules, CA, USA). Samples with an equivalent amount of protein were boiled for $5 \mathrm{~min}$ with Laemmli SDS-PAGE sample buffer, and then analyzed by SDS-PAGE. Proteins were electroblotted onto nitrocellulose membranes, blocked by incubation for $30 \mathrm{~min}$ in PBS containing 5\% (wt/vol) free-fat dry milk, and incubated sequentially with primary and secondary antibodies, both diluted in blocking solution, for $1 \mathrm{~h}$ at room temperature, or overnight at $4{ }^{\circ} \mathrm{C}$. Chemiluminescence protein detection was performed using SuperSignal West Pico (Thermo Fisher Scientific). $\beta$-actin was used as an internal loading control.

\subsection{In vitro Proteasomal Activity Assay}

Proteasome activity was quantitatively assessed in $\mathrm{H} 4$ cell extracts using the $\beta 5$-selective fluorogenic substrate succinyl-leucine-leucine-valine-tyrosine-4-methyl-7-courmarylamide (Suc-LLVY-AMC, Calbiochem, Burlington, MA, USA) using an adapted protocol [37]. Briefly, cells were left untreated or treated for $4 \mathrm{~h}$ with different amounts of CZM (between 2 and $10 \mu \mathrm{M}$ ) or with $10 \mu \mathrm{M}$ MG132. Cells were lysed in lysis buffer (20 mM Tris-HCl, pH 7.2, 1 mM EDTA, 1 mM dithiothreitol (DTT) and $0.1 \%(v / v)$ Nonidet P-40) supplemented with a cocktail of protease inhibitors (Sigma-Aldrich). Lysates were cleared by centrifugation at $16,000 \times \mathrm{g}$ for $20 \mathrm{~min}$ at $4{ }^{\circ} \mathrm{C}$, and protein concentration was determined with a protein assay dye reagent (Bio-Rad Laboratories, Hercules, CA, USA). Soluble 
extracts $(20 \mu \mathrm{g})$ were incubated for $60 \mathrm{~min}$ at $37^{\circ} \mathrm{C}$ in proteasome assay buffer $(50 \mathrm{mM}$ Tris- $\mathrm{HCl}, \mathrm{pH} 7.2$, $1 \mathrm{mM}$ DTT, 0,5 mM EDTA and $100 \mu \mathrm{M}$ Suc-LLVY-AMC) all dispensed in triplicate into a 96-well black opaque plate (Nunc, Thermo Fisher Scientific). Proteasome activity was measured by monitoring the production of free AMC using a Synergy HT Multi-detection Microplate Reader (BioTek Instruments, VT, USA) with excitation and emission wavelengths of 360 and $460 \mathrm{~nm}$, respectively, and the data were obtained by Gen5 Version 2.09.1 data analysis software (BioTek Instruments, VT, USA). Statistical significance was determined by One-Way ANOVA, followed by Dunnett's test. Value of $p<0.01(* *)$ and $\left.p<0.001{ }^{(* *}\right)$ were regarded as statistically significant and are indicated in the figure.

\subsection{Immunofluorescence}

Cells grown on glass coverslips were washed with PBS and fixed in $4 \%(v / v)$ paraformaldehyde for $30 \mathrm{~min}$ at room temperature. After fixation, cells were washed in PBS and permeabilized with $0.2 \%$ $(v / v)$ Triton X-100 in PBS for $10 \mathrm{~min}$ at room temperature. Cells were incubated with the indicated primary antibodies diluted in immunofluorescence buffer (PBS containing 10\% $(v / v)$ FBS and $0.1 \%(w / v)$ saponin for $30 \mathrm{~min}$ at $37^{\circ} \mathrm{C}$. Coverslips were washed in PBS and incubated with the corresponding Alexa-conjugated secondary antibody diluted in immunofluorescence buffer for $30 \mathrm{~min}$ at $37^{\circ} \mathrm{C}$. For nuclei staining, cells were washed with PBS and incubated for $10 \mathrm{~min}$ at room temperature with $0.1 \mathrm{mg} / \mathrm{mL}$ DAPI. After the final wash, coverslips were mounted onto glass slides with Fluoromount-G (SouthernBiotech, Birmingham, AL, USA).

\subsection{Fluorescence Microscopy}

Images of fixed cells were acquired by using a TCS SP8 laser-scanning confocal microscope (Leica Microsystems, Wetzlar, Germany) equipped with a $63 \times$ oil immersion objective (1.4 NA), $405 \mathrm{~nm}$, $488 \mathrm{~nm}$ and $561 \mathrm{~nm}$ laser lines, with Photomultiplier (PMT), a hybrid detector system (Leica HyD) and the Leica Application Suite LAS X software. For quantification of fluorescent signals, 8-bit images were acquired under identical settings avoiding signal saturation and corrected for background signal on each image. The corrected fluorescent signal in each cell of each image was used in Image J (version 1.44o; Wayne Rasband, NIH, http://imagej.nih.gov) to determine the total integrated pixel intensity per cell area. Colocalization analyses were performed with sets of immunofluorescence images (Z-stack, with $0.2 \mu \mathrm{m}$ intervals) of the same cells for each marker. Quantification of the acquired images was performed with the ICY software (Quantitative Image Analysis Unit, Institut Pasteur, $\mathrm{http} / /$ icy.bioimageanalysis.org/) using the protocols plugin to create a pipeline to analyze the images in batch, the active contours plugin to perform the cell segmentation, the hk-means plugin for threshold detection, the wavelet spot detector plugin for spot detection and the colocalization studio plugin for colocalization analysis.

For live cell imaging assays, $\mathrm{H} 4$ cells were grown in glass bottom culture dishes (MatTek Corporation, Ashland, MA, USA) and transiently transfected for 48-h with KDELR-VSVG-YFP, using TransIT-LT1 Transfection Reagent (Mirus Bio LLC, Madison, Wi, USA) according to the manufacturer's protocol. Before the live cell imaging assay, the culture medium was replaced with phenol red-free DMEM supplemented with HEPES (10 mM, pH 7.4), and the cells were treated with CZM $(10 \mu \mathrm{M})$ at $32{ }^{\circ} \mathrm{C}$ in a controlled temperature chamber in the TCS SP8 laser-scanning confocal microscope. Cells were kept at $32{ }^{\circ} \mathrm{C}$ to allow KDELR-VSVG-YFP localization on the Golgi, followed by a shift in temperature to $40^{\circ} \mathrm{C}$. Imaging was done with a $63 \mathrm{x}$ oil immersion objective (1.4 NA), running the Leica Application Suite LAS X software, acquiring 8-bit images at 1-min interval for $15 \mathrm{~min}$ at $40^{\circ} \mathrm{C}$ (488 laser for excitation; HyD: 510-550 nm; $1024 \times 1024$ pixels; frame average 1). Quantification of the acquired images was performed with the MetaMorph Software version 7.0.

\subsection{Golgi Reconstruction and Golgi Volume and Area Measurements}

H4 and HeLa cells stably expressing KDELR1-GFP, under the specified conditions, were fixed and immunostained with anti-GM130 or anti-Giantin, respectively. The immunofluorescence protocol 
was performed as described above to visualize the Golgi structure. For Golgi volume and area measurements, Z-stack $(250 \mathrm{~nm})$ fluorescence images were acquired by using a TCS SP8 laser-scanning confocal microscope (Leica Microsystems, Wetzlar, Germany) equipped with a 63x oil immersion objective (1.4 NA) running the Leica Application Suite LAS X software. Images were then processed with ImageJ software version FIJI to remove the background by using a threshold. The threshold images were then visualized using the "3D Viewer" plugin. The Golgi volume was quantified using ImageJ software version FIJI by setting a threshold region to select only the Golgi fluorescence. Then, the Golgi structures were separated by ROI (Regions of Interest), and the individual Golgi volume was measured with the plugin "Voxel Counting". The Golgi volume in $\mu \mathrm{m}^{3}$ was determined by the number of voxels contained in the stack of images (voxel $0.2 \times 0.2 \times 0.25 \mathrm{~nm}$ ). The Golgi area was quantified using ICY software, and the Golgi marker GM130 was used to determine the ROI. To separate the specific signal from the background, the "k means threshold" plugin was used, using the same threshold level to all images. Data analysis was performed using GraphPad Prism 6 (GraphPad Software, La Jolla, CA, USA), and the results are represented in graphs depicting the mean \pm SEM of at least 20 cells. The statistical significance of the data was determined with Student's T-test. The value of $p<0.001(* *)$ was regarded as statistically significant and is indicated in the respective figures.

\subsection{Densitometric Quantification and Statistical Analysis}

The amount of immunoblot signal was estimated using Image J software version 1.48v (Wayne Rasband, NIH, http://imagej.nih.gov). For each condition, protein bands were quantified from at least three independent experiments in order to ensure adequate statistical power. Data analysis was performed using Microsoft Excel 2013 for Windows (Redmond, WA, USA) or GraphPad Prism Results are represented in graphs depicting the mean \pm standard deviation. Statistical significance of data comparisons from two groups comparisons was determined with Student's T-test for parametric data. Values of $p<0.05\left(^{*}\right), p<0.01\left(^{* *}\right), p<0.001\left(^{* * *}\right)$ were regarded as statistically significant and are indicated in the figures. The statistical significance of data from many groups was analyzed using One-Way ANOVA, followed by Tukey's test in order to evaluate pair-wise comparisons. The value of $p<0.05$ was regarded as statistically significant and indicated in the figure in different letters above bars mean.

\section{Results}

\subsection{High-Content siRNA Screening Revealed PSMD14 Deubiquitinating Enzyme as a Novel Regulator of Protein Trafficking}

To investigate the contribution of the ubiquitinome in protein membrane trafficking, an automated HCS using a human small interfering RNA (siRNA) "ubiquitinome" library was performed consisting of 1187 siRNA duplex pools targeting all known and predicted Ub-genes (Supplementary Materials). This library was used previously in mammalian screening assays [33,34], and includes E1 activating enzymes $(0.8 \%)$, E2 conjugating enzymes (4.7\%), E3 Ub ligases (61.2\%), UBD-containing proteins (12.8\%), DUBs $(8.8 \%)$, SUMO-specific proteases (SENPs) $(0.2 \%)$ and others $(11.4 \%)$ (Figure 1A). This library was used to identify novel regulators of protein membrane trafficking using an $\mathrm{H} 4$ neuroglioma cell line stably expressing APP-EGFP, a cell line previously characterized and used in siRNAs knockdown experiments $[24,30,38]$. We standardized the basal (background) and maximum fluorescence intensity by analyzing the total fluorescence of silenced and non-silenced APP-EGFP, respectively. A reduction in total fluorescence intensity from $100 \%$ to $6 \%$ was observed with the EGFP siRNA, compared to the non-target (NT) siRNA with a Z factor of 0.69 (Figure 1B). Representative images of basal and maximum levels of total fluorescence intensity in reporter cells are shown in Figure 1C. Cells were further assessed with a primary siRNA screening consisting of a pool of four-different siRNA duplexes for each of the 1187 genes selected. Each siRNA targeted a distinct region to minimize their off-targets effects [39]. Figure 1D shows a summary of the results with all siRNA pools tested and normalized in respect to the expression of the NT siRNA. Among the 1187 tested genes, we found that the highest total fluorescence increase (4.15-fold increase) corresponded to protein PSMD14 (POH1, also known as 
Rpn11/MPR1/SS13/CepP1) (Figure 1D), a subunit of the 19S regulatory particle (RP) of the proteasome, which has DUB activity $[40,41]$. Representative images of reporter cells knock-down (KD) of PSMD14 in comparison to cells transfected with NT siRNA are shown in Figure 1E.

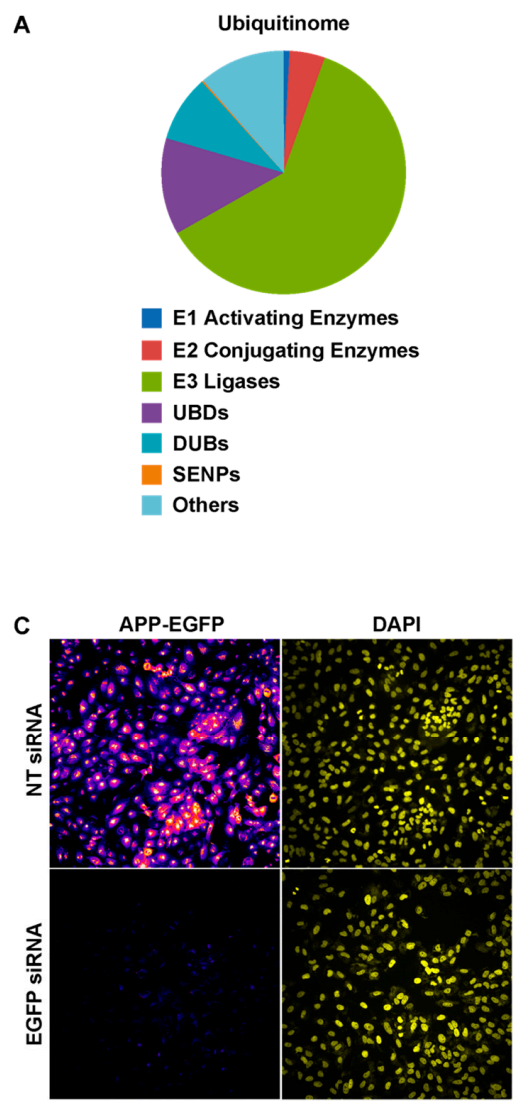

B
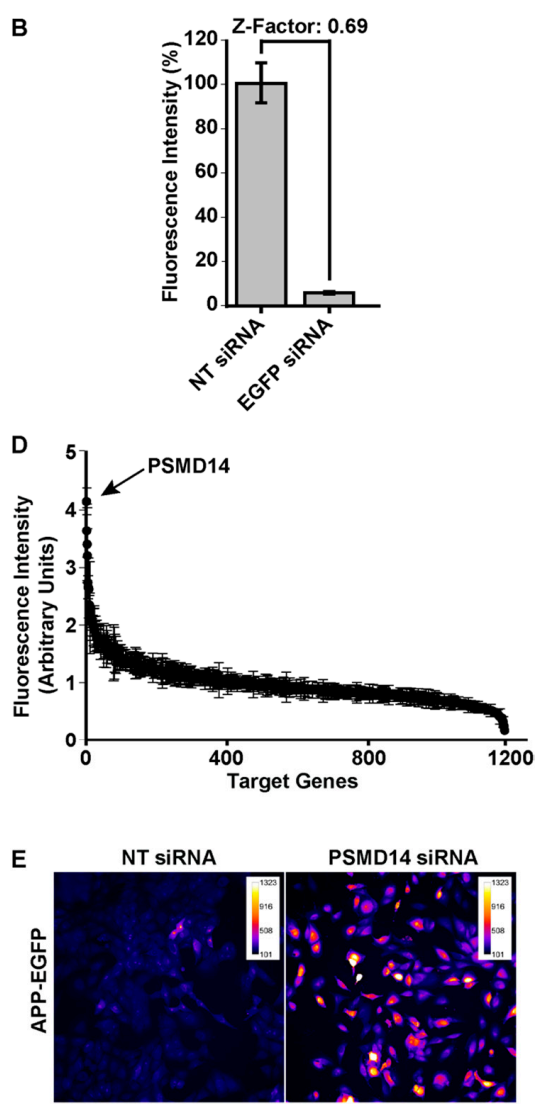

Figure 1. High-content siRNA screening assay revealed PSMD14 as a novel regulator of amyloid precursor protein (APP) levels. (A) Graphical distribution of the targets evaluated in the primary high content siRNA screening using the siRNA "ubiquitinome" library in H4 cells. (B) Quantification of the total fluorescence intensity of reporter APP-EGFP cells transfected for $72 \mathrm{~h}$ with NT siRNA and EGFP siRNA. Bars represent the mean \pm SD with a statistical $\mathrm{Z}$ factor $=0.69$. (C) High content images $(20 \times)$ captured in reporter APP-EGFP cells transfected for $72 \mathrm{~h}$ with non-target (NT) siRNA and EGFP siRNA. (D) Graphical representation of total fluorescence intensity of all 1187 genes analyzed in primary siRNA screening with the reporter APP-EGFP cells. PSMD14 appears indicated as the top hit. (E) High content images (20x) in pseudo color of reporter APP-EGFP cells transfected for $72 \mathrm{~h}$ with siRNA SMARTpool targeted against PSMD14 (PSMD14 siRNA) in comparison to cells transfected with NT siRNA. The fluorescence intensity in these images was reduced to avoid saturation with the PSMD14 siRNA. Scale Bar of the images indicates the scale of fluorescence intensity.

Further, we validated these results by analyzing the effect of PSMD14 KD on the levels of full-length endogenous APP in parental $\mathrm{H} 4$ cells by western blot. The effect of all four PSMD14 siRNAs in KD cells tested on endogenous APP levels are shown in Figure 2A (first panel, lanes 3-6) and compared to un-transfected cells (Mock) or cells transfected with NT siRNA (Figure 2A, first panel, lanes 1 and 2, respectively). In addition, we found that silencing PSMD14 caused a strong increase in high molecular weight $\mathrm{Ub}$ conjugates, consistent with the role of PSMD14 as a proteasomal subunit with DUB activity (Figure 2A, second panel, lanes 3-6 compared to lanes 1 and 2). For quantification analysis, we used the most effective siRNA for the reduction in PSMD14 expression that corresponded to siRNA\#1 according to quantitative reverse transcription PCR (RT-qPCR) (Figure 2D). We found a 3.13-fold increase in full-length endogenous APP levels in PSMD14 KD cells, compared to Mock cells (Figure 2B). 
In addition, we observed a 5.22-fold decrease in PSMD14 levels (Figure 2C). Moreover, efficiency KD of PSMD14 was determined by RT-qPCR (Figure 2D) and confirmed by western blot (Figure 2A, third panel, lanes 3-6 compared to lanes 1 and 2). Finally, to evaluate whether the increase in APP protein levels in PSMD14 KD cells could be the result of an up-regulation of APP transcription, APP mRNA levels were evaluated by RT-qPCR observing no significant changes (Figure 2E). Altogether, these findings indicate that the silencing of PSDM14 caused a robust increase in APP protein levels, a finding that could suggest impairment in its turnover due to trafficking alterations.

A

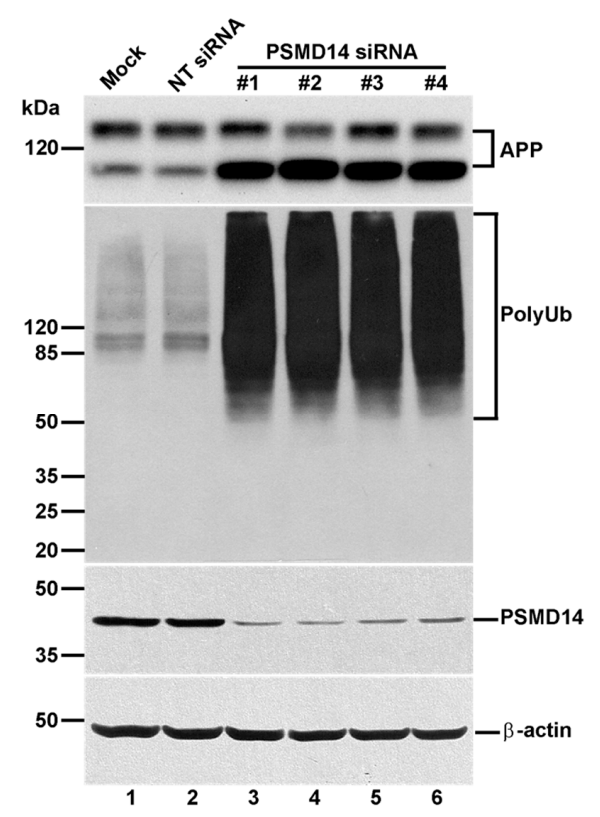

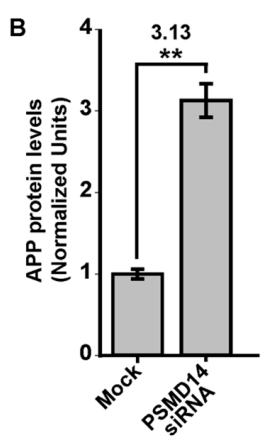

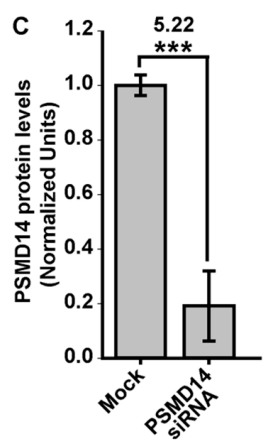

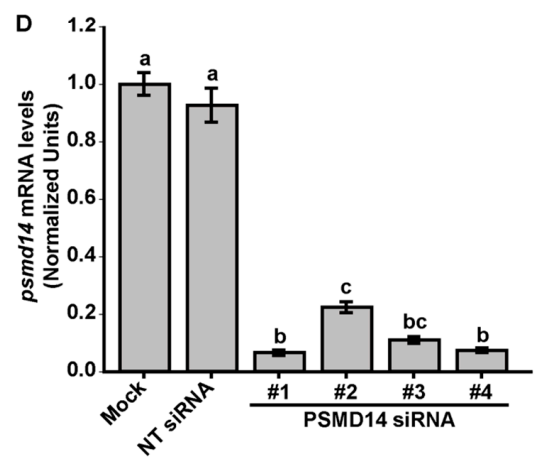

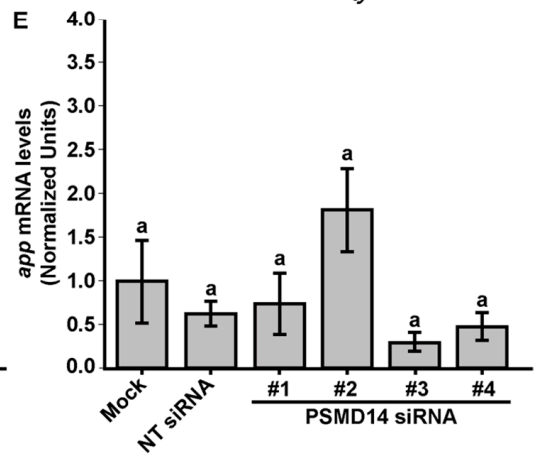

Figure 2. PSMD14 is validated as a regulator of the endogenous APP levels. (A) Protein extracts of parental H4 cells either untransfected (Mock), transfected with NT siRNA, or transfected with four different PSMD14 siRNA sequences for $72 \mathrm{~h}$ were analyzed by western blot. Polyclonal antibodies to endogenous APP (CT695) and to Ub (that recognizes all types of Ub conjugates), and monoclonal antibodies to PSMD14 (clone D18C7) and to $\beta$-actin (clone BA3R), were tested. The position of molecular mass markers are indicated on the left. Densitometric quantification of the levels of endogenous APP (B) and PSMD14 (C) in H4 cells transfected with PSMD14 siRNA\#1, compared to untransfected cells (Mock). Statistical significance was determined by Student's t-test. Bars represent the mean \pm SD of biological replicates (APP $n=5$; PSMD14 $n=4$ ). ${ }^{* *} p<0.01$ and ${ }^{* * *} p<0.001$. (D) mRNA levels of $p s m d 14$ and (E) mRNA levels of app were measured using RT-qPCR from parental H4 cells transfected for $72 \mathrm{~h}$. All data were normalized for TATA binding protein expression in either untransfected cells (Mock), cells transfected with NT siRNA or cells transfected with four different PSMD14 siRNAs duplexes. Statistical significance was determined by One-Way ANOVA, followed by Tukey's test. Bars represent the mean \pm SD of biological replicates ( $\operatorname{simd14} n=3$; app $n=3$ ). Different letters above the mean bars apply to significant differences between groups $p<0.01$. 
3.2. Acute Inhibition of the Deubiquitinating Enzyme PSMD14 of the 19S RP Accumulates APP in a Swollen Golgi Apparatus

To determine whether PSMD14 is involved in the control of endogenous APP levels, we investigated the effect of incubating cells with Capzimin (CZM), a potent and specific inhibitor of the DUB activity of PSMD14 [42], a subunit of the 19S RP of the proteasome (Figure 3A). We observed that CZM led to a significant increment in full-length endogenous APP levels in a dose-dependent manner, compared to untreated cells (Figure 3B,C). Interestingly, compared to untreated cells, and in contrast to $\mathrm{CZM}$, treatment with a standard concentration of $10 \mu \mathrm{M}$ MG132, a reversible inhibitor of the $\beta 1, \beta 2$ and $\beta 5$ subunits of the $20 \mathrm{~S}$ catalytic core of the proteasome [43,44] (Figure 3A), caused a significant decrease in full-length endogenous APP levels (Figure 3B,C). To confirm the inhibition of PSMD14 by CZM, the effect of this inhibitor on the levels of high molecular weight Ub conjugates was tested, comparing it with MG132. In agreement with the effect of PSMD14 KD, it was observed that CZM caused a robust increase in high molecular weight $\mathrm{Ub}$ conjugates in a dose-dependent manner, finding a maximum effect with $10 \mu \mathrm{M}$ CZM (Figure 3D). However, we noticed that $10 \mu \mathrm{M}$ MG132 caused a more powerful increase in $\mathrm{Ub}$ conjugates (Figure 3D). To confirm the accumulation of $\mathrm{Ub}$ conjugates by these treatments, we performed immunofluorescence analysis. We found that $10 \mu \mathrm{M} \mathrm{CZM}$ (Figure 3E, middle panel) and $10 \mu \mathrm{M}$ MG132 (Figure 3E, right panel) showed the appearance of Ub conjugates puncta, compared to untreated cells (Figure 3E, left panel), which showed the expected cytosolic distribution of $\mathrm{Ub}$. Together, our results confirm that acute inhibition of PSMD14 by CZM replicates the phenotype obtained by PSMD14 KD regarding the impact on the endogenous APP levels. Thus, CZM offers a pharmacological tool addressing whether the activity of PSDM14 is required for APP membrane trafficking.

To unveil this possibility, immunofluorescence analysis of endogenous APP in parental $\mathrm{H} 4$ cells was performed. We observed that the treatment with $10 \mu \mathrm{M} \mathrm{CZM}$ resulted in a perinuclear redistribution of APP, which is highly indicative of Golgi apparatus localization (Figure 4D, compared to 4A). Moreover, similar to the PSMD14 KD, it was observed that the CZM treatment caused a significant 2.50-fold increase in APP total fluorescence intensity compared to untreated cells (Figure 4G). We also observed a significant 1.92-fold increase in the amount of APP in the area positive to the Golgi matrix protein GM130 (GM130), compared to the total area (Figure 4F, compared to $4 \mathrm{C}$ and Figure $4 \mathrm{H}$ ). Moreover, we observed that the treatment with CZM caused a significant 1.30-fold increase in the total cell area (Figure 4I). In addition, we found that CZM caused the swelling of the Golgi apparatus (Figure 4E compared to Figure 4B), a phenotype that is shown in a zoom in Figure 4J. To confirm this phenotype, measurements of GM130 images were performed from confocal 3D reconstructions from the Z-stacks of cells treated with CZM (Figure 4K). We observed a 1.53-fold increase in the Golgi apparatus volume in CZM treated cells, compared to control cells (Figure 4L). Similar results were observed in quantitative 2D image analysis, observing a significant 2.53-fold increase in the Golgi apparatus area upon CZM treatment (Figure S3). Altogether, our results show that acute inhibition of PSMD14 by CZM accumulates APP in a swollen Golgi apparatus. These findings strongly suggest that CZM impairs the Golgi apparatus due to perturbations of the trafficking through this organelle. 
A B
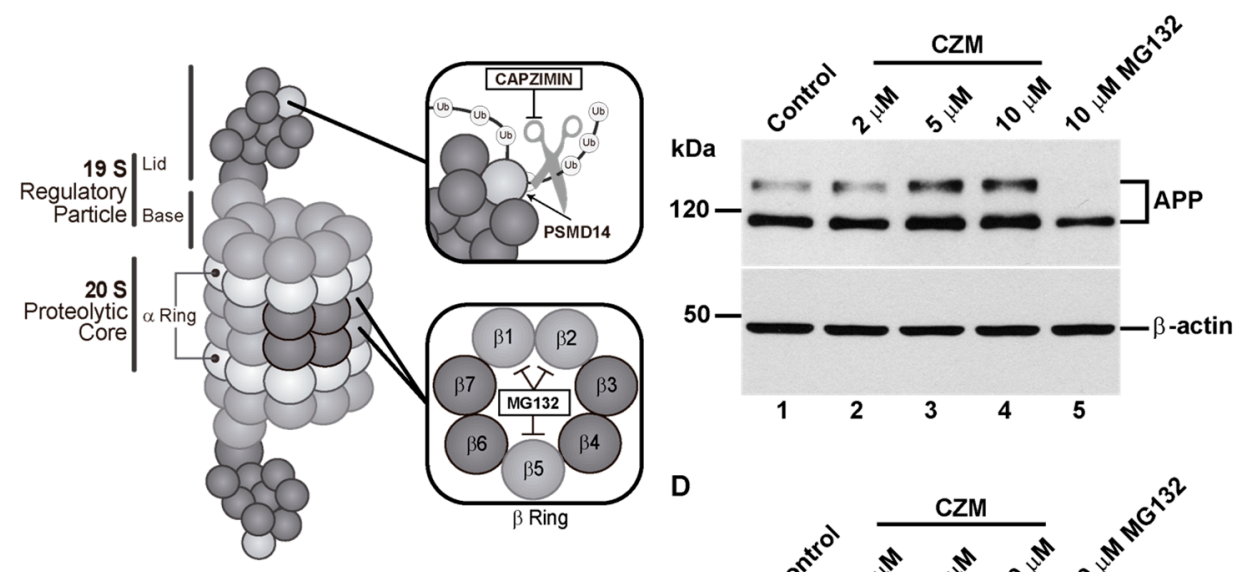

C
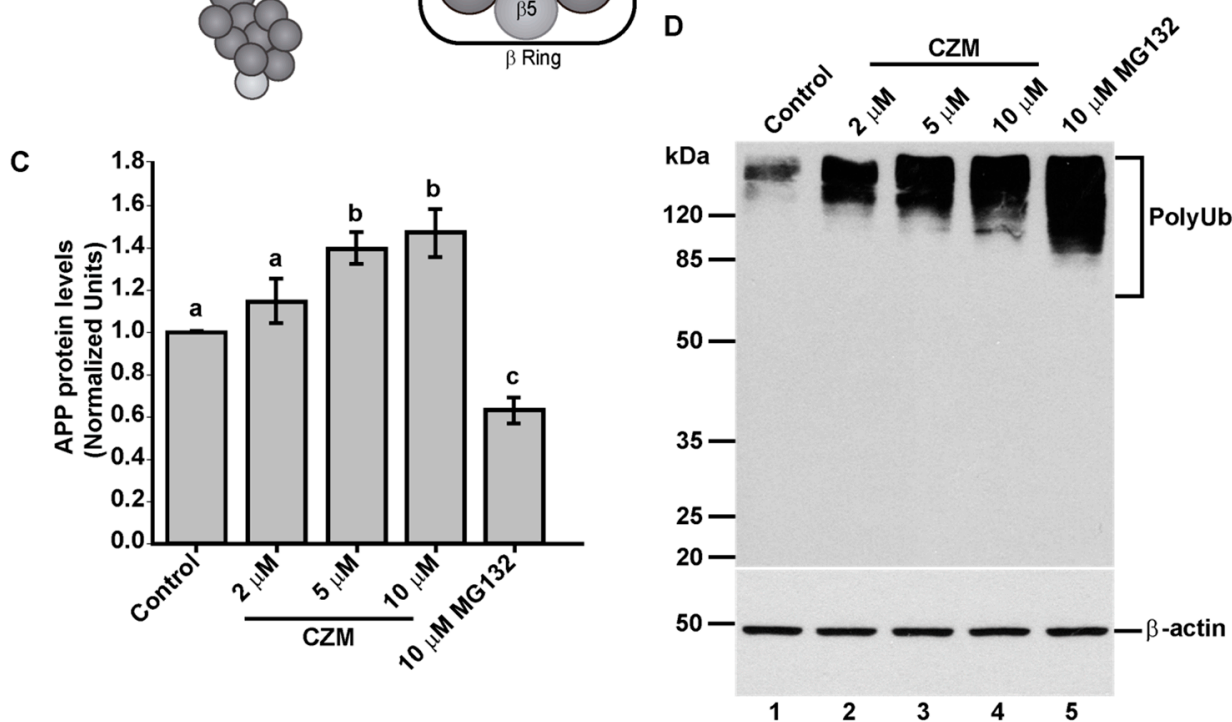

E

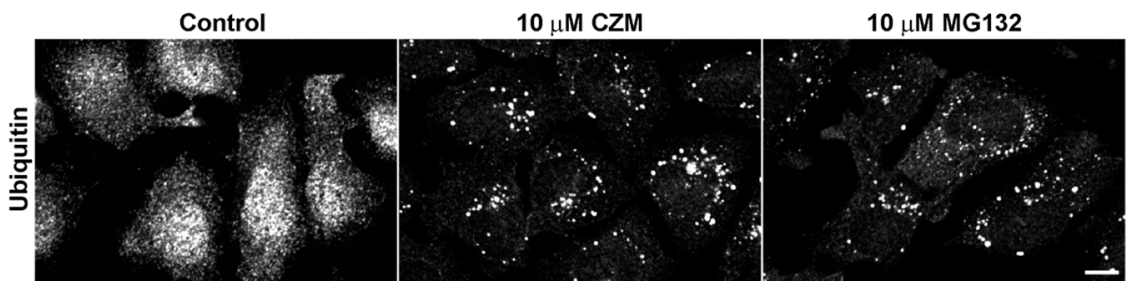

Figure 3. Acute inhibition of PSMD14 by Capzimin CZM shows a similar phenotype as that of PSMD14 $\mathrm{KD}$ on the levels of APP and high molecular weight $\mathrm{Ub}$ conjugates. (A) Schematic diagram of the molecular targets of Capzimin and MG132 in the 19S RP and 20S catalytic core of the proteasome, respectively. (B) Parental H4 cells were treated either with vehicle (DMSO; Control), or increasing doses of CZM for $4 \mathrm{~h}$, or MG132 for $6 \mathrm{~h}$. Protein extracts were analyzed by western blot with a polyclonal antibody to endogenous APP. Monoclonal antibody to $\beta$-actin (clone BA3R) was used as a loading control. The position of molecular mass markers is indicated on the left. (C) Densitometric quantification of APP protein levels as shown in (D). Statistical significance was determined by one-way ANOVA, followed by Tukey's test. Bars represent the mean \pm SD of biological replicates $(n=4)$. Different letters above the mean bars apply to significant differences between groups $p<0.05$. (D) Parental $\mathrm{H} 4$ cells were treated as in (B), and the protein extracts were analyzed by western blot with a polyclonal antibody to $\mathrm{Ub}$ that recognizes all types of $\mathrm{Ub}$ conjugate. Monoclonal antibody to $\beta$-actin (clone BA3R) was used as a loading control. The position of molecular mass markers is indicated on the left. (E) Immunofluorescence microscopy images of the cellular localization of $\mathrm{Ub}$ in parental $\mathrm{H} 4$ cells treated with either the vehicle (DMSO; Control), CZM for $4 \mathrm{~h}$ or MG132 for $6 \mathrm{~h}$. Cells were fixed, permeabilized and stained with a mouse monoclonal antibody to Ub (clone P4D1) followed by Alexa-488-conjugated donkey anti-mouse IgG. Scale bar, $10 \mu \mathrm{m} .(n=3)$. 


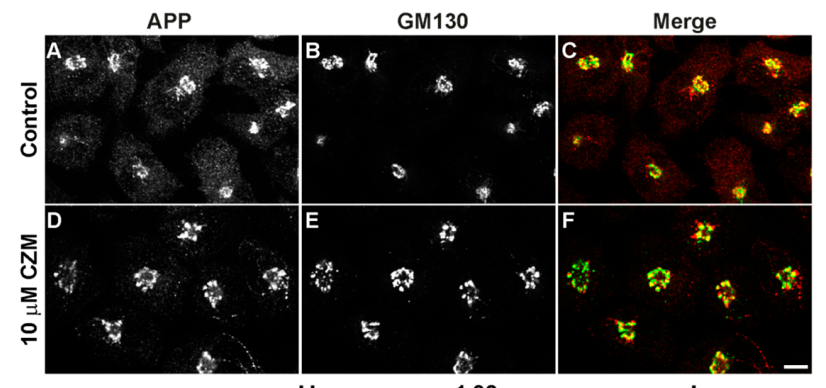

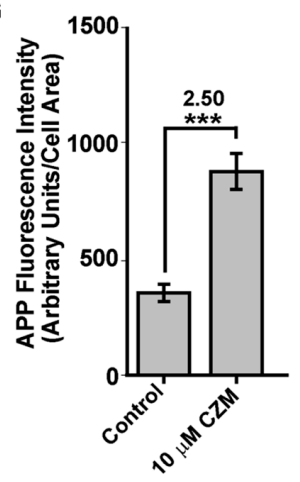

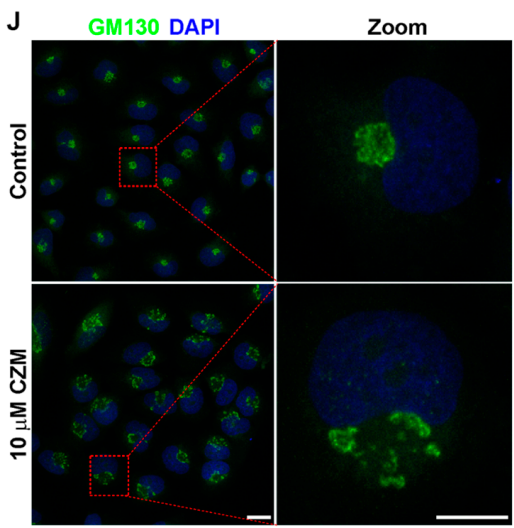

H
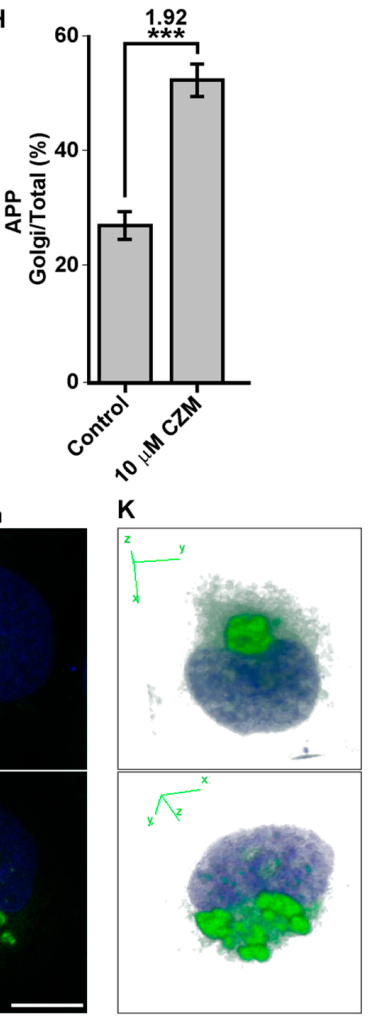

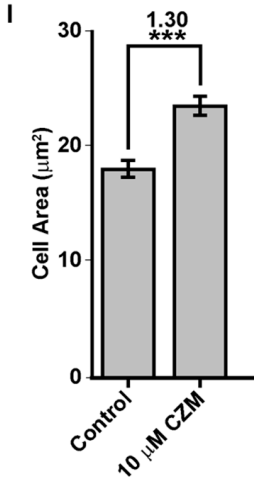

$\mathbf{L}$

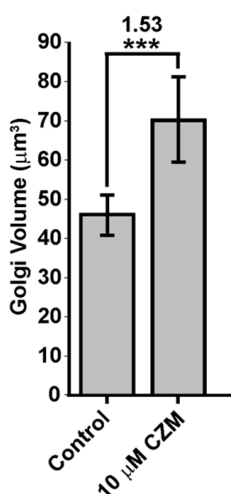

Figure 4. Acute inhibition of PSMD14 by CZM triggers the accumulation of APP in a swollen Golgi apparatus. Immunofluorescence analysis of endogenous APP in $\mathrm{H} 4$ parental cells treated either with the vehicle (DMSO; Control) (A-C) or CZM (D-F) for $4 \mathrm{~h}$. Cells were fixed, permeabilized, and double stained with a rabbit polyclonal antibody to APP (CT695) (A,D) and a mouse monoclonal antibody to GM130 (clone35/GM130) (B,E), followed by Alexa-594-conjugated donkey anti-Rabbit IgG and Alexa-488-conjugated donkey anti-Mouse IgG. Merging of the images generated the third picture (C,F). Scale bar, $10 \mathrm{~mm}$. (G) Quantitative analysis of the mean of total fluorescence intensity of APP upon treatment with CZM, in comparison to control cells. The statistical significance was determined by Student's t-test. Bars represent the mean \pm SD of the fluorescent signal per cell area ( $n=43$ cells). ${ }^{* * *} p<0.001$. (H) Quantitative analysis of the fraction of APP colocalizing with GM130 under CZM treatment and compared to control cells. Statistical significance was determined by Student's t-test. Bars represent the mean $\pm \mathrm{SD}$ of the fluorescent signal per cell area $\left(n=43\right.$ cells). ${ }^{* * *} p<0.001$. (I) Quantitative analysis of the cell area. Statistical significance was determined by Student's t-test. Bars represent the mean $\pm \mathrm{SD}$ of the cell area $\left(n=43\right.$ cells) ${ }^{* *} p<0.001$. (J) Immunofluorescence microscopy analysis of GM130 in parental H4 cells treated either with the vehicle (DMSO; Control) or CZM for $4 \mathrm{~h}$. Cells were fixed, permeabilized and stained with mouse monoclonal antibody to GM130 (clone 35/GM130) followed by Alexa-488-conjugated donkey anti-mouse IgG, and nuclei were stained with DAPI. Scale bar, $10 \mu \mathrm{m}$. (K) 3D reconstructions of the Golgi apparatus using GM130 as Golgi marker were generated from Z-stacks $(250 \mathrm{~nm}$ ). (L) Golgi Volume was measured from 3D reconstructions as shown in (K). Statistical significance was determined by Student's t-test. Bars represent the means \pm $\operatorname{SEM}(n=20$ cells $) .{ }^{* * *} p<0.001$. 


\subsection{Acute Inhibition of the Deubiquitinating Enzyme PSMD14 Perturbs Golgi-to-ER Retrograde Transport}

The Golgi apparatus is a highly dynamic organelle that requires fine regulation of trafficking pathways in order to maintain its size, shape and composition. In particular, it has been shown that Golgi-to-ER retrograde transport plays a crucial role in the maintenance of Golgi morphology. Indeed, inhibition of this specific trafficking pathway results in a significant swelling of this organelle [32,45-49]. To investigate whether the swelling of the Golgi by the inhibition of PSMD14 with CZM could be the result of the inhibition of the Golgi-to-ER retrograde transport, we first validated our findings in HeLa cells. We measured Golgi apparatus volume in 3D reconstructions from the Z-stacks of untreated HeLa cells or treated with CZM and MG132 by using Giantin as a Golgi apparatus reporter. Similar to our findings in $\mathrm{H} 4$ cells, we found that the inhibition of PSMD14 DUB activity by CZM causes a 2.14-fold increase in Golgi apparatus volume (Figure 5A, middle panel compared to the left panel and 5B). Interestingly, in contrast to CZM, we observed that MG132 caused no effect on Golgi apparatus volume (Figure 5A, right panel compared to the left panel and 5B), strongly suggesting that Golgi homeostasis is regulated by the PSMD14 DUB activity. Then, we investigated whether this phenotype was the result of Golgi-to-ER retrograde transport inhibition. We assessed the distribution of stably overexpressed KDEL (Lys-Asp-Glu-Leu) Receptor 1 (KDELR1) fused to GFP (KDELR1-GFP) in HeLa cells. As was previously reported [32,50], overexpressed KDELR1-GFP is mostly distributed to the ER due to its efficient transport from the Golgi apparatus to the ER (Figure 5C, left panel and 5D). Thus, impairment of Golgi-to-ER retrograde transport causes the accumulation of KDELR1-GFP in the Golgi apparatus, working as an assay to identify novel regulators of this pathway [32]. Interestingly, we found that CZM caused a rapid time-dependent accumulation of KDELR1-GFP at the Golgi apparatus, observing a maximal effect after 90 min of treatment (Figure S4). At this time, we observed a significant 1.50-fold increase in the amount of KDELR1-GFP within the Giantin-positive Golgi apparatus, compared to the total area (Figure 5C, middle panel compared to the left panel, and 5D). As before, we tested the effect of MG132, observing no effect on the distribution of KDELR1-GFP (Figure 5C, right panel compared to left panel, and 5D), which strongly supports that MG132 has no effect on Golgi-to-ER retrograde transport. Next, to confirm the blockage of Golgi-to-ER retrograde transport by the acute inhibition of the PSMD14, we tracked the redistribution of the transiently overexpressed thermo-sensitive KDELR1-VSVG-YFP chimera (vesicular stomatitis virus G protein fused to KDEL receptor 1 and YFP) in HeLa cells upon treatment with CZM by live cell imaging at different temperatures. Briefly, at a permissive temperature of $32{ }^{\circ} \mathrm{C}$, KDELR1-VSVG-YFP cycles between the Golgi apparatus and the ER, showing distribution mainly at the Golgi apparatus. Upon shifting to a restrictive temperature of $40^{\circ} \mathrm{C}$ KDELR1-VSVG-YFP is progressively accumulated at the ER due to its specific retention in this compartment at this temperature. In addition, as the Golgi-to-ER retrograde transport is not affected at $40^{\circ} \mathrm{C}$, the rapid decay of KDELR1-VSVG-YFP fluorescence at the Golgi apparatus is a measurement used to evaluate inhibition of Golgi-to-ER retrograde transport pathway [51]. We found that in control cells, nearly $50 \%$ of the fluorescence of KDELR1-VSVG-YFP decayed after $15 \mathrm{~min}$ of shifting the temperature to $40^{\circ} \mathrm{C}$ (Figure $5 \mathrm{E}$, upper panels and 5F) indicating that retrograde transport is working normally [51]. In contrast, when cells were treated with CZM, the decay of KDELR1-VSVG-YFP fluorescence was not apparent, confirming that acute inhibition of the PSMD14 blocked Golgi-to-ER retrograde transport (Figure 5E, lower panels and 5F). In contrast, MG132-treated cells showed similar results to controls (data not shown), confirming that the $20 \mathrm{~S}$ proteasome has no effect on retrograde transport. Importantly, we found that CZM is able to block retrograde transport for short times having no effect on the catalytic activity of the 20S proteasome (Figure S5). In contrast, a rapid and robust inhibition of the catalytic activity of the 20S proteasome was observed with MG132 (Figure S5). These findings strongly indicate that acute inhibition of PSMD14 DUB activity by CZM acts as a powerful blocker of Golgi-to-ER retrograde transport, explaining the swelling of the Golgi apparatus and the accumulation of protein cargoes such as APP at this location. 
A

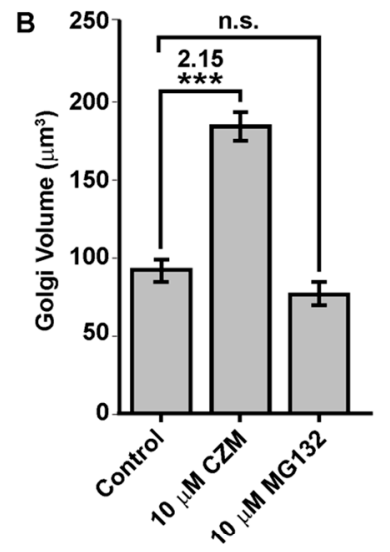

C
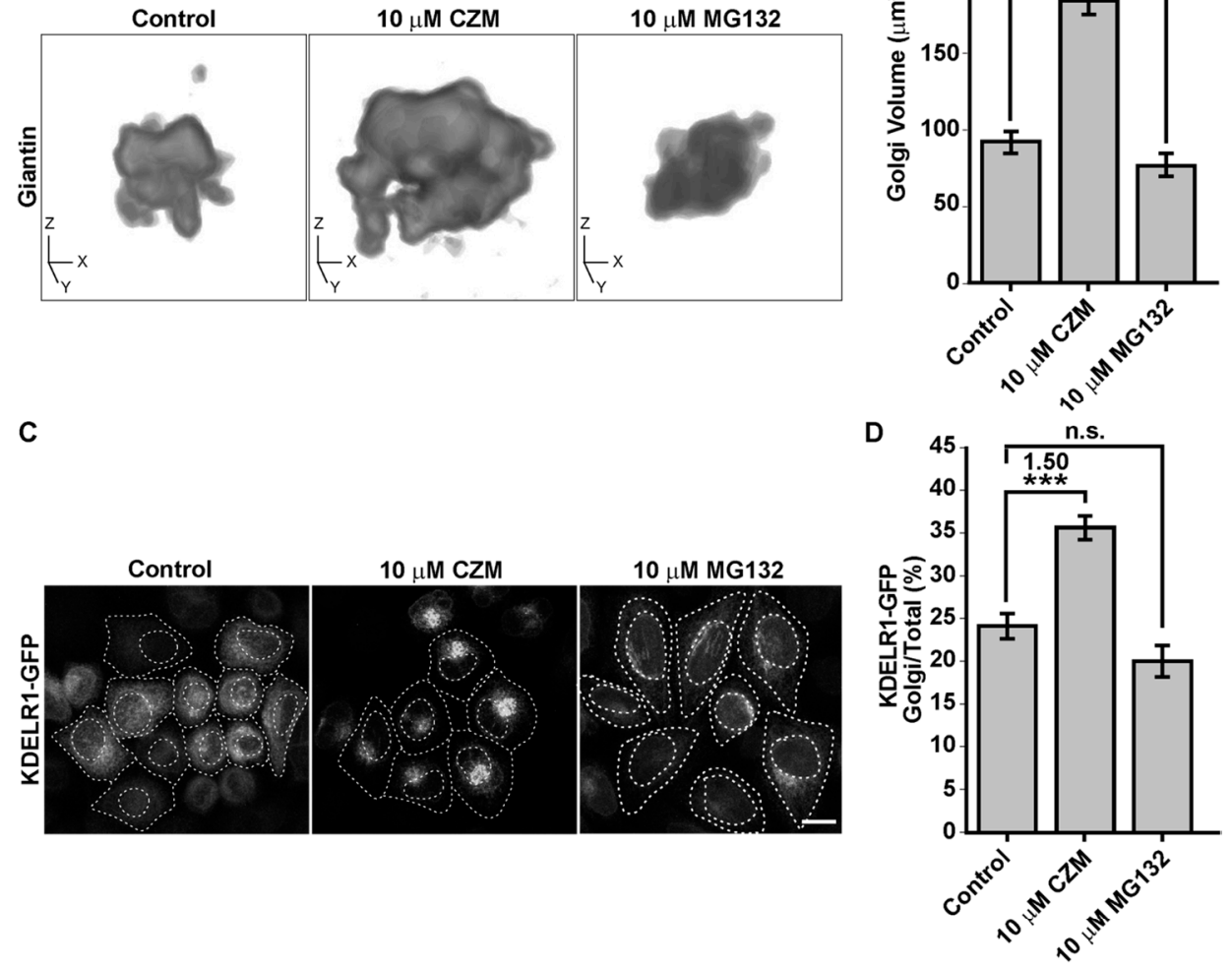

$\mathbf{E}$

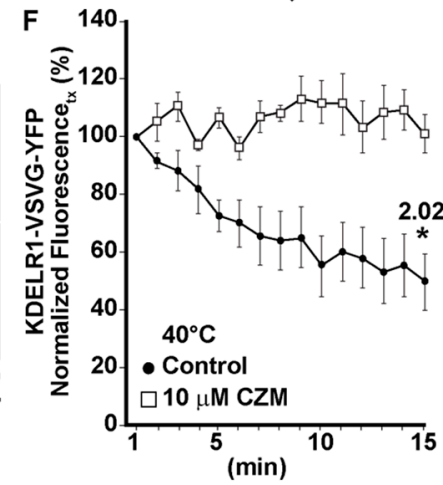

Figure 5. The PSMD14 DUB inhibitor CZM impairs Golgi-to-ER retrograde transport. (A) Three-dimensional reconstructions of the Golgi apparatus using giantin as a Golgi marker were generated from Z-stacks ( $250 \mathrm{~nm}$ ) obtained from HeLa cells stably expressing KDELR1-GFP treated for 90 min either with vehicle (DMSO; Control), CZM or MG132. (B) Golgi volume was measured from $3 \mathrm{D}$ reconstructions as shown in (A). Statistical significance was determined by Student's t-test. Bars represent the means \pm SEM ( $n=30$ cells). ${ }^{* * *} p<0.001$. (C) HeLa cells stably expressing KDELR1-GFP were treated for $90 \mathrm{~min}$ either with vehicle (DMSO; Control), CZM or MG132. Cells were fixed, and representative confocal images were acquired. (D) Measurement of giantin and total KDELR1-GFP total fluorescent intensity. Statistical significance was determined by Student's t-test. Bars represent the means \pm SEM ( $n=34$ cells). ${ }^{* * *} p<0.001$. (E) H4 cells were transiently transfected to express the thermo-sensitive retrograde transport reporter KDELR-VSVG-YFP. Cells were kept at $32{ }^{\circ} \mathrm{C}$ to allow KDELR-VSVG-YFP localization at the Golgi. Cells were then shifted to $40{ }^{\circ} \mathrm{C}$ (restrictive temperature) and images acquired at $1 \mathrm{~min}$ interval for $15 \mathrm{~min}$. (F) Quantitative image analysis was performed to measure the integrated fluorescence of KDELR-VSVG-YFP at the Golgi at $1 \mathrm{~min}$ interval for $15 \mathrm{~min}$. Statistical significance was determined by Student's t-test. Bars represent the mean \pm SEM ( $n=3$ cells). ${ }^{*} p<0.05$. 


\subsection{Inhibition of Golgi-to-ER Retrograde Transport by CZM Has a Negative Impact on Macroautophagy}

Several lines of evidence have shown that Golgi-to-ER retrograde transport plays a relevant role in autophagosome biogenesis at the level of the ER [52-55]. In addition, it has been shown that PSMD14 participates in the activation of the aggresome clearance by cleaving K63 Ub chains of aggregate proteins [56,57]. Thus, we investigated the effect of acute inhibition of PSMD14 DUB activity on the levels of the classical marker microtubule-associated protein 1 light chain 3B (LC3B) [58], compared to the treatment with MG132 (Figure 6A). We observed that CZM alone did not increase the levels of LC3B-II (Figure 6A and Figure S6B). As expected, and in contrast to CZM, higher levels of LC3B-II were found with MG132 treatment (Figure 6A). In agreement with these findings, we observed that CZM alone did not increase the number of autophagosomes (Figure $6 \mathrm{E}$ compared to 6B), in contrast to the effect of MG132 (Figure S6A). In addition, parental H4 cells were treated under nutrient starvation with Earle's balanced salt solution (EBSS), an established culture medium used for the activation of autophagosomal formation [59]. As expected, we found that starvation strongly increased the number of autophagosomes (Figure 6C), compared to cells treated under normal nutrients conditions (Figure 6B). In contrast, it was observed that treatment with CZM abolished the appearance of autophagosomes upon EBSS treatment (Figure 6D compared to 6C). We also tested the effect of CZM in cells under normal nutrients conditions, but in the absence or presence of Torin-1, a potent and selective inhibitor of mammalian target of rapamycin complexes (mTORC1/2), a trigger of autophagosomal formation [60]. Similar to the results with EBSS, we observed that CZM prevented the appearance of autophagosomes promoted by Torin-1 (Figure 6G compared to 6F). To confirm these results, we quantified the number of LC3-positive structures under all conditions tested, observing a significant decrease in the number of autophagosomes when cells, treated with EBSS solution or Torin-1, were also treated with CZM (Figure 6H). In addition, we biochemically validated these results performing western blot analysis of endogenous LC3B (Figure 6I). We found that the levels of LC3B-II were strongly increased with EBSS or Torin-1 treatment (Figure 6I, lanes 2 and 4). In contrast, when cells were treated with EBSS or Torin-1 in the presence of CZM, LC3B-II levels did not change (Figure 6I, lanes 3 and 5) compared to control cells (Figure 6I, lane 1), results that are quantified and depicted in Figure $6 \mathrm{~K}$. Interestingly, this biochemical analysis also showed that CZM increased LC3B-I levels under all conditions tested (Figure 6I, lanes 3, 5 and 6, and Figure 6J) compared to control cells (Figure 6I, lane 1) suggesting that the reduction of the autophagosomal structures caused by CZM was not due to a reduction in LC3B total levels. Altogether, these results confirm that acute inhibition of PSMD14 DUB activity acts as a potent blocker of autophagosome biogenesis induced by EBSS or Torin-1. In addition, these findings suggest that blockage of autophagosomal biogenesis could be a consequence of Golgi-to-ER retrograde transport inhibition. 

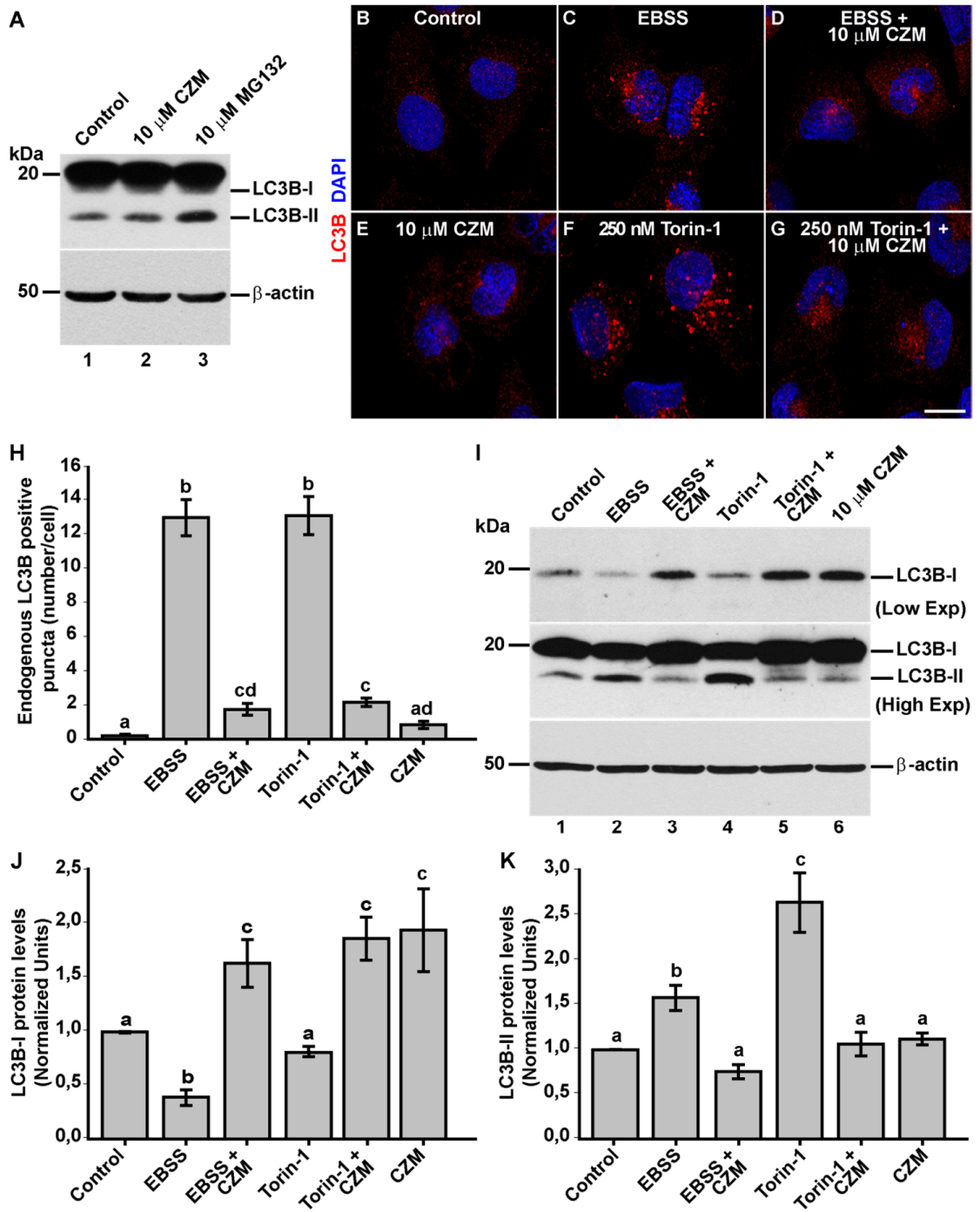

Figure 6. Inhibition of autophagosome formation by CZM. (A) Parental H4 cells were treated either with the vehicle (DMSO; Control), CZM for $4 \mathrm{~h}$ or MG132 for $6 \mathrm{~h}$ and protein extracts were analyzed by western blot with a polyclonal antibody to LC3B. Monoclonal antibody to $\beta$-actin (clone BA3R) was used as a loading control. The positions of the molecular mass markers are indicated on the left. Immunofluorescence microscopy analysis of the subcellular localization of endogenous LC3B in parental H4 cells treated with either the vehicle (DMSO; Control) (B), EBSS for $4 \mathrm{~h}$ (C), CZM for $6 \mathrm{~h}$ (E) or Torin-1 for $4 \mathrm{~h}$ (F). EBSS (D) and Torin-1 (G) were tested using a 2-h pretreatment with CZM followed by the treatment with EBSS or Torin- 1 for $4 \mathrm{~h}$ in the presence of CZM. Cells were fixed, permeabilized and stained with a rabbit polyclonal antibody to LC3B followed by Alexa-594-conjugated donkey anti-Rabbit IgG, and nuclei were stained with DAPI. Scale bar $10 \mu \mathrm{m}$. (H) Quantification of the puncta positive to LC3B. Statistical significance was determined by one-way ANOVA, followed by Tukey's test. Bars represent the mean $\pm \operatorname{SEM}(n=50$ cells). Different letters above the mean bars indicate the significant differences between groups $p<0.05$. (I) Protein extracts from parental $\mathrm{H} 4$ cells treated as in (B-G) were analyzed by western blot with a rabbit polyclonal antibody to LC3B. Monoclonal antibody to $\beta$-actin (clone BA3R) was used as a loading control. The position of molecular mass markers is indicated on the left. (J) Densitometric quantification of LC3B-I levels and (K) LC3B-II levels. Statistical significance was determined by One-Way ANOVA, followed by Tukey's test. Bars represent the mean \pm SEM of biological replicates (LC3B-I $n=3$; LC3B-II $n=3$ ). Different letters above the mean bars indicate the significant differences between groups $p<0.05$. 
3.5. Inhibition of Golgi-to-ER Retrograde Transport by CZM Accumulates RAB1A and ATG9A at the Golgi Apparatus

To evaluate this hypothesis, we tested the effect of acute inhibition of the PSMD14 DUB activity on the distribution of proteins implicated in the initial steps of autophagosome formation, which traffics in early compartments of the secretory pathway. We first tested RAB1A, a small GTPase with an essential role in the initiation of autophagy, facilitating the recruitment of the unc-51-like kinase 1 (ULK1) complex to subdomains of the ER, a crucial early step during autophagosome formation [61,62]. We found that CZM treatment caused a redistribution of RAB1A to the perinuclear zone (Figure 7A). Measuring these images confirmed a significant increase in RAB1A in this area (Figure 7B), a result that was accompanied by a decrease in RAB1A in the cell periphery defined as radial zone (Figure 7B). Importantly, we found that RAB1B was not affected by the same condition (data not shown). Moreover, we observed that RAB1A was distributed in the swollen Golgi apparatus, similar to GM130, upon CZM treatment (Figure S7). With the same aim, we studied the distribution of ATG9A, an essential transmembrane protein involved in macroautophagy, which plays a crucial role in the early steps of autophagosome formation [63,64]. ATG9A-containing vesicles are formed from the Golgi apparatus translocating to the ER to form the initiation site at the ER for autophagosome formation [65]. Similar to RAB1A, we found that acute inhibition of PSMD14 caused a redistribution of ATG9A to the perinuclear zone, together with a decrease in its distribution in the radial zone (Figure $7 \mathrm{C}$ ). The quantification analysis of these images is shown in Figure 7C. Moreover, and similar to RAB1A, we observed that ATG9A is distributed to the swollen GM130-Golgi apparatus area upon CZM treatment (Figure S8). These results strongly indicate that blockage of Golgi-to-ER retrograde transport by acute inhibition of PSMD14 DUB activity causes the retention at the Golgi apparatus of key proteins implicated in early steps of autophagosome formation. The PSDM14-dependent inhibition of autophagy explains the accumulation of APP at the Golgi apparatus since macroautophagy has been recently demonstrated as a positive regulator of protein secretion from the Golgi apparatus [66]. Collectively, these results show the strong interplay between membrane transport and autophagy through a novel mechanism involving the proteasome complex through the deubiquitinating activity of PSMD14.

A

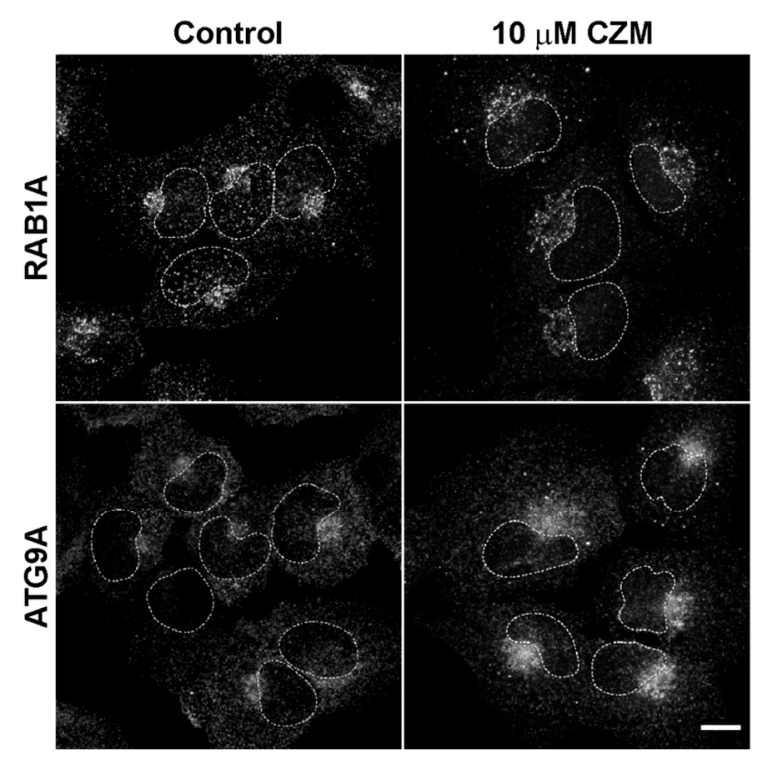

Figure 7. Cont. 

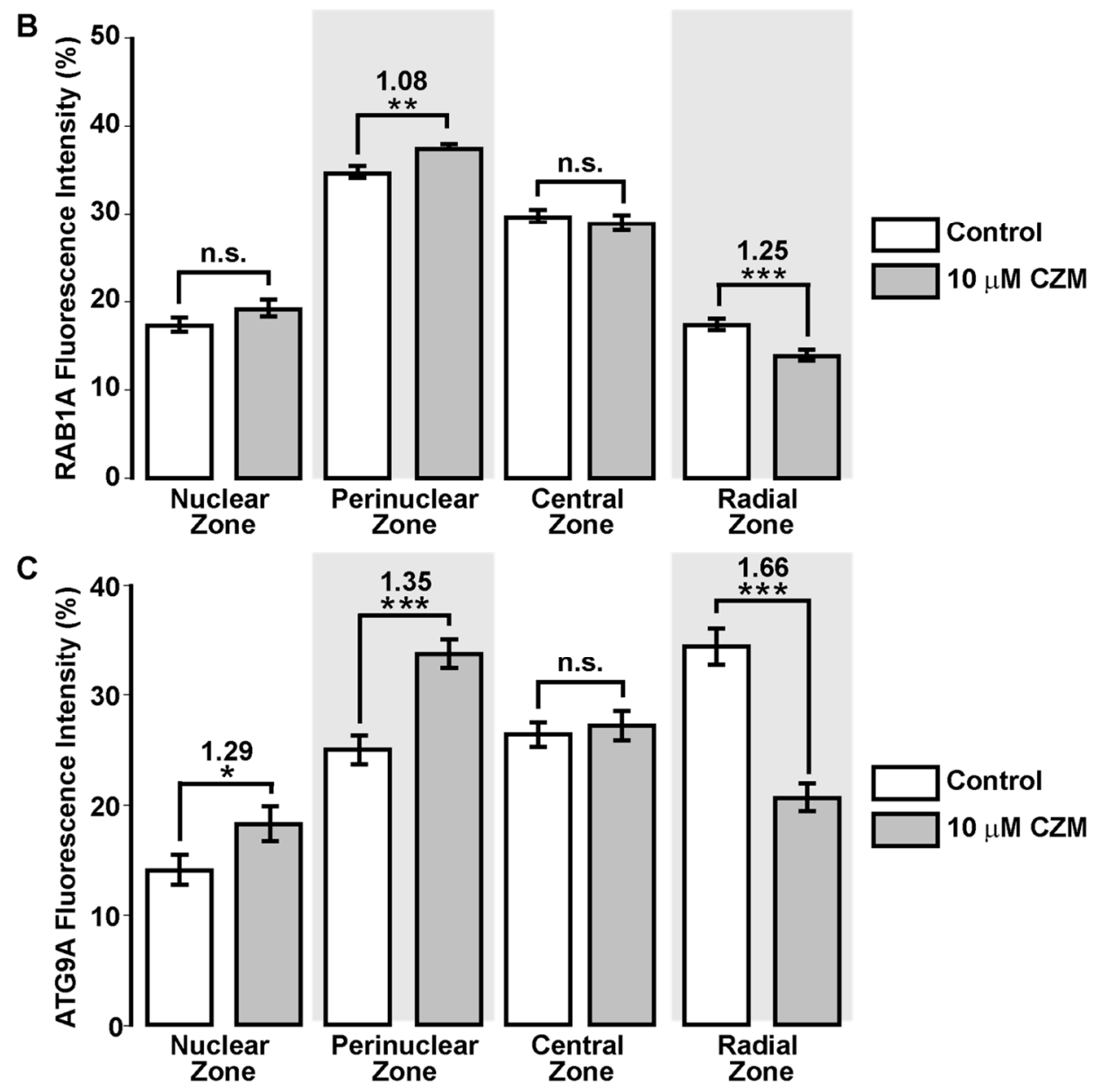

Figure 7. Redistribution of RAB1A and ATG9A to the Golgi apparatus with CZM. (A) Immunofluorescence analysis of endogenous RAB1A and ATG9A in H4 parental cells treated for $4 \mathrm{~h}$ either with the vehicle (DMSO; Control) (left panel) or CZM (right panel). Cells were fixed, permeabilized, and stained with a rabbit monoclonal antibody to RAB1A (clone D3X9S) (upper panel) and a rabbit monoclonal antibody to ATG9A (clone EPR2450(2)) (lower panel), followed by Alexa-594-conjugated donkey anti-Rabbit IgG. Scale Bar, $10 \mu \mathrm{m}$. (B) Quantitative analysis of the fluorescence intensity of RAB1A upon treatment with CZM, in comparison to control cells. Statistical significance was determined by Student's t-test. Bars represent the mean \pm SEM of the fluorescent signal per cell area ( $n=227$ cells). ${ }^{* *} p<0.01 ;{ }^{* * *} p<0.001$; n.s., not significant. (C) Quantitative analysis of the fluorescence intensity of ATG9A upon treatment with CZM, in comparison to control cells. Statistical significance was determined by Student's t-test. Bars represent the mean \pm SEM of the fluorescent signal per cell area $\left(n=95\right.$ cells). ${ }^{*} p<0.05 ;{ }^{* * *} p<0.001 ;$ n.s., not significant.

\section{Discussion}

We report here that PSMD14 DUB activity, a subunit of the 19S RP of the proteasome, functions as a novel regulator of autophagosome formation. To our knowledge, this is the first report demonstrating that impairment of the proteasome can have a negative impact on the initiation of macroautophagy. In general, several studies have shown that the inhibition of the 20S catalytic core with the use of blockers of the $\beta$-subunits triggers the enhancement of the biogenesis of LC3B-positive autophagosomes [67-72]. In this regard, we showed that MG132 caused an increment of the LC3II/LC3I ratio and a significant decrease in full-length endogenous APP levels, strongly indicating a reduction in APP by macroautophagy [38,73-76]. Here, we show that blockage of the PSMD14 DUB activity, a component of the 19S RP, plays a negative role in the biogenesis of LC3B-positive autophagosomes, given new insights about the control of macroautophagy. 
In addition, and because only CZM but not MG132 blocked Golgi-to-ER retrograde transport, a pathway implicated in the initiation of autophagosomes [52-55], we postulated that PSMD14 DUB activity controls macroautophagy by a process independent of bulk proteasomal degradation but dependent on K63-Ub chains. In agreement with this possibility, K63-Ub chains have been directly involved in the control of protein membrane trafficking in C. elegans [77] and as a regulator of mTORC and macroautophagy [78,79]. Likewise, free unanchored K63-Ub chains released in a PSMD14-dependent manner have shown to be crucial in coordinating the elimination of protein aggregates by macroautophagy [56], relocating the aggregates to the aggresome for final autophagic clearance by a mechanism related with deacetylase HDAC6 activity [80]. Here, we unveil the first insight into the regulation of Golgi-to-ER retrograde transport by K63-Ub chains, highlighting the deubiquitinating enzyme PSMD14 as a key regulator in the control of early events of the secretory pathway. In this regard, and in agreement with the role of the deubiquitination in membrane protein trafficking [81,82], we hypothesize that Golgi-to-ER retrograde transport must be controlled by the deubiquitination of cytosolic proteins modified with $\mathrm{K} 63-\mathrm{Ub}$ chains.

In this regard, key regulatory proteins involved in Golgi-to-ER transport are regulated by the state of ubiquitination/deubiquitination. In yeast, the deletion of the DUB Ube3p and its co-factor Bre5p accumulates ubiquitinated $\beta^{\prime}$-COP facilitating its rapid degradation by the proteasome $[81,83]$. As $\beta^{\prime}-$ COP is a subunit of the COP-I coatomer complex, a key machinery implicated in Golgi-to-ER retrograde transport, reduction in $\beta^{\prime}$-COP levels perturbs this trafficking pathway [81]. Interestingly, it has been previously proposed that full-length APP can traffic retrogradely between the Golgi apparatus and the ER mediated by the COP-I complex. In fact, the silencing of COP-I subunits by siRNAs induces APP accumulation at the Golgi apparatus, which reduces APP proteolytic processing [84].

Two other proteins that participates in this retrograde trafficking pathway, such as PKA and UVRAG [32,85], have been shown to be regulated by ubiquitination. Blockers of PKA signaling cause the inhibition of this trafficking pathway, a process that is accompanied by the swelling of the Golgi apparatus [32,49]. It has been shown that the catalytic PKA subunit (PKAc) is ubiquitinated by the CHIP E3 ligase, resulting in proteasomal degradation of PKAc and signaling shutdown [86]. UVRAG mediates the interaction of $\beta^{\prime}-\mathrm{COP}$ with ER tethers and COP-I coatomer for efficient fusion of retrograde vesicles to the ER, a crucial step during Golgi-to-ER retrograde transport [53]. UVRAG is ubiquitinated by SMURF1 [87] and its silencing causes the swelling of the Golgi apparatus and the inhibition of the Golgi-to-ER retrograde transport [53]. Whether these proteins are regulated by $\mathrm{K} 63-\mathrm{Ub}$ chains is unknown and should be further addressed.

In addition, we propose that Golgi-to ER retrograde transport inhibition by PSMD14 dysfunction might result in the accumulation of structural and/or autophagy regulatory elements. In fact, the inhibition of PSMD14 caused the accumulation of ATG9A at the Golgi. ATG9A is a multispanning membrane protein essential for autophagy $[63,64]$. ATG9A is actively transported through Golgi-to-ER retrograde transport [65] and participates as a key player in the biogenesis of autophagosomes [63,88]. Moreover, along with the accumulation of ATG9A at the Golgi, we found increased levels of RAB1A at the Golgi apparatus. RAB1A is an essential small GTPase that participates in the recruitment of the ULK1 complex to subdomains of the ER for autophagy initiation [61,62]. Interestingly, and similar to PSMD14 inhibition, ATG9A deficiency causes an increase in LC3B-I levels, accompanied by a reduction in the number of autophagosome structures $[63,88,89]$. Together, our results strongly support that PSMD14 inhibition perturbs autophagosome biogenesis due to the sequestration of key proteins of this process at the Golgi apparatus. In addition, it supports the hypothesis of a closed intersection between Golgi-to-ER retrograde and autophagy pathway $[53,85]$. whereas PSMD14 DUB activity emerged as a new regulatory element of this intersection.

The PSDM14-dependent inhibition of macroautophagy might affect protein secretion from the Golgi apparatus since autophagy has been recently demonstrated as a positive regulator of this process [66], which is in agreement with the strong accumulation of APP at the Golgi apparatus. The crosstalk between macroautophagy and protein secretion was recently discovered, observing that 
the arrival of cargo to the Golgi apparatus induces lysosome repositioning to the perinuclear region along with the activation of the autophagy flux by a mechanism dependent on KDELR signaling [66]. Importantly, the abolishment of either lysosomal repositioning or autophagosome biogenesis strongly reduced cargo exit from the Golgi apparatus, demonstrating that protein transport from the Golgi apparatus to the plasma membrane requires macroautophagy [66]. Collectively, the results demonstrate the strong functional interplay between membrane transport and macroautophagy mediated by a novel mechanism involving the proteasome complex through the deubiquitinating activity of PSMD14 (Model in Figure 8). We propose that inhibition of PSDM14 DUB activity by CZM is a new strategy for causing inhibition of the Golgi-to-ER retrograde pathway. Thus, CZM should now be considered as a new pharmacological tool to study the impact of Golgi-to-ER retrograde transport inhibition in other cell biology processes, such as autophagy. Moreover, because CZM was discovered as a new drug for cancer treatment [42], it would now be interesting to investigate whether part of its anti-cancer effects could be the result of inhibiting the Golgi-to-ER retrograde pathway. Interestingly, recent studies have shown that PSMD14 is upregulated (mRNA and protein levels) in different tumoral cell types $[90,91]$. Whether cancer cells are more dependent on the Golgi-to-ER retrograde pathway than normal cells, as it happens regarding the mechanisms of protein quality control [92], is still unclear. CZM could offer an interesting tool to evaluate this hypothesis, positioning PSMD14 as a promising target for therapeutic intervention.

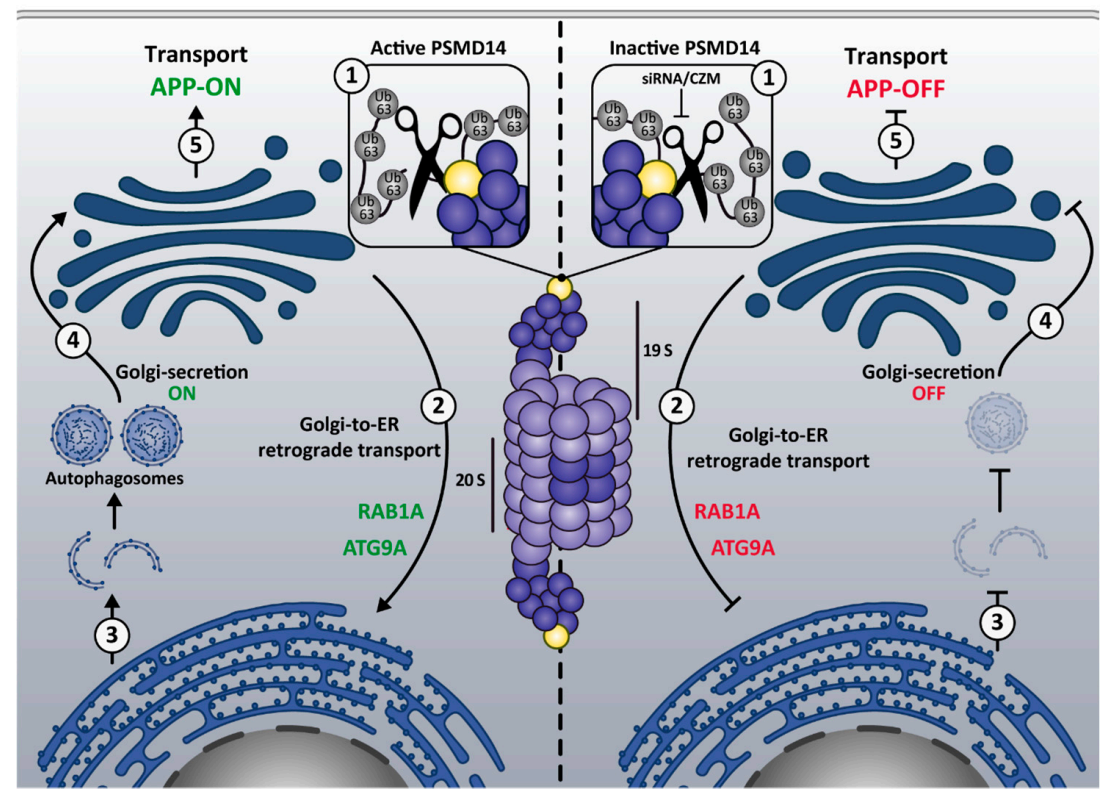

Figure 8. Model of the mechanism underlying the regulation of protein membrane trafficking and macroautophagy by the proteasome 19S RP PSMD14 DUB activity. The model depicts the closed interplay between membrane transport and macroautophagy by a novel mechanism involving the proteasome complex through the deubiquitinating activity of PSMD14. We propose that active PSMD14 and the K63-Ub chains (1, left panel) positively regulate Golgi-to-ER retrograde transport (2, left panel), a pathway implicated in the retrieval of key proteins for autophagosome biogenesis and macroautophagy (3, left panel). Reduction of free K63-Ub chains by inactive PSMD14 (1, right panel) results on the blockage of Golgi-to-ER retrograde transport (2, right panel) causing the accumulation of ATG9A and RAB1A at the Golgi apparatus. Thus, blockage of Golgi-to-ER retrograde transport inhibits the biogenesis of autophagosomes and macroautophagy (3, right panel). Macroautophagy has been recently demonstrated to act as a potent positive regulator of protein transport from the Golgi apparatus to the cell surface (Golgi-secretion ON; 4, left panel). Thus, inhibition of macroautophagy upon inactive PSMD14 (siRNA/CZM) blocks protein transport from the Golgi apparatus to the cell surface (Golgi-secretion OFF; 4 right panel), explaining the effect on APP transport (5 left and 5 right panels). 
Supplementary Materials: The following are available online http://www.mdpi.com/2073-4409/9/3/777/s1. Figure S1: siRNA sequences directed against human PSMD14 used for Validation Stage; Figure S2: Primer pairs sequences used for RT-qPCR; Figure S3: The PSMD14 DUB inhibitor CZM increases the Golgi apparatus area; Figure S4: CZM causes the accumulation of KDELR1-GFP at the Golgi apparatus; Figure S5: Effect of CZM on proteasome activity; Figure S6: Effect of CZM and MG132 on basal macroautophagy; Figure S7: Distribution of RAB1A upon CZM treatment; Figure S8: ATG9A is distributed in the swollen Golgi apparatus upon CZM treatment.

Author Contributions: Conceptualization, H.A.B., A.R.-F. and P.V.B.; Data curation, H.A.B., K.C, A.E.G, G.E.V., Y.C, S.H., E.A.-M., C.C.-T., A.R.-F. and P.V.B.; Formal analysis, H.A.B., K.C., A.E.G., G.E.V., Y.C., S.H., E.A.-M., C.C.-T., B.K., A.R.-F. and P.V.B; Funding acquisition, R.T.H, A.R.-F. and P.V.B.; Investigation, H.A.B., G.K., A.E.G., G.E.V., E.A.-M., C.C.-T. and S.B.; Methodology, H.A.B, J.C., A.R.F. and P.V.B.; Resources, G.E.V., S.B., A.S., G.K., B.K., G.A.M., J.C., R.T.H., A.R.-F. and P.V.B; Supervision, A.R.-F. and P.V.B.; Writing-original draft, H.A.B., A.R.-F. and P.V.B; Writing-review and editing, H.A.B, S.B., A.S., B.K., G.A.M., J.C., A.R.-F., R.T.H and P.V.B. All authors have read and agreed to the published version of the manuscript.

Funding: This research was funded by Fondo Nacional de Desarrollo Científico y Tecnológico of Chile (FONDECYT; http://www.conicyt.cl/fondecyt) No. 1171649 to P.V.B. \& No. 11150532 to A.R.F.; Associative Investigation Program (PIA; https://www.conicyt.cl/pia) including No. ACT-172066 to P.V.B. \& No. AFB-170005 to P.V.B.; Academy Insertion Program (PAI; http://www.conicyt.cl/pai) No. 79150075 to A.R.F.; Fondo de Equipamiento Científico y Tecnológico of Chile (FONDEQUIP; http://www.conicyt.cl/fondequip) No. EQM150118 to P.V.B.; Cooperation International Programme (CONICYT-RCUK; https://www.conicyt.cl/pci) No. DPI20140068 to P.V.B.; H.A.B., A.E.G., and G.E.V. were supported by National Ph.D Fellowships No. 21130315, 201110746 and 21130511, respectively, (CONICYT; https://www.conicyt.cl/becasconicyt); Programa de Mejoramiento de la Calidad y la Equidad de la Educación superior, MECESUP AUS1203 and Vicerrectoría de Investigación de la Universidad Austral de Chile No. D \#2015-02 to H.A.B., D \#2013-07 to A.E.G. and D \#2015-05 to G.E.V.

Acknowledgments: We thank Gonzalo Astroza (Universidad Austral de Chile) and Ellis Jaffray (GRE, University of Dundee) for technical assistance. Raymond Deshaies (Division of Biology \& Biological Engineering, California Institute of Technology) and Yuyong Ma (Department of Chemistry and Biochemistry, University of California) for providing Capzimin for this study.

Conflicts of Interest: The authors declare no conflict of interest. The funders had no role in the design of the study; in the collection, analyses, or interpretation of data; in the writing of the manuscript, or in the decision to publish the results.

\section{References}

1. Shinde, S.R.; Maddika, S. Post translational modifications of Rab GTPases. Small GTPases 2017, 9, 49-56. [CrossRef] [PubMed]

2. Luo, P.M.; Boyce, M. Directing Traffic: Regulation of COPI Transport by Post-translational Modifications. Front. Cell Dev. Boil. 2019, 7, 190. [CrossRef] [PubMed]

3. Li, M.; Brooks, C.L.; Wu-Baer, F.; Chen, D.; Baer, R.; Gu, W. Mono- Versus Polyubiquitination: Differential Control of p53 Fate by Mdm2. Science 2003, 302, 1972-1975. [CrossRef] [PubMed]

4. Komander, D.; Rape, M. The Ubiquitin Code. Annu. Rev. Biochem. 2012, 81, 203-229. [CrossRef] [PubMed]

5. Foot, N.; Henshall, T.; Kumar, S. Ubiquitination and the Regulation of Membrane Proteins. Physiol. Rev. 2017, 97, 253-281. [CrossRef]

6. Pelham, H.R. Membrane Traffic: GGAs Sort Ubiquitin. Curr. Boil. 2004, 14, R357-R359. [CrossRef]

7. Yang, B.; Kumar, S. Nedd4 and Nedd4-2: Closely related ubiquitin-protein ligases with distinct physiological functions. Cell Death Differ. 2010, 17, 68-77. [CrossRef]

8. Tan, J.; Evin, G. $\beta$-Site APP-cleaving enzyme 1 trafficking and Alzheimer's disease pathogenesis. J. Neurochem. 2012, 120, 869-880. [CrossRef]

9. Raiborg, C.; Stenmark, H. The ESCRT machinery in endosomal sorting of ubiquitylated membrane proteins. Nature 2009, 458, 445-452. [CrossRef]

10. Ren, X.; Hurley, J.H. VHS domains of ESCRT-0 cooperate in high-avidity binding to polyubiquitinated cargo. EMBO J. 2010, 29, 1045-1054. [CrossRef]

11. Clague, M.J.; Liu, H.; Urbe, S. Governance of Endocytic Trafficking and Signaling by Reversible Ubiquitylation. Dev. Cell 2012, 23, 457-467. [CrossRef] [PubMed]

12. Haglund, K. Distinct monoubiquitin signals in receptor endocytosis. Trends Biochem. Sci. 2003, 28, 598-604. [CrossRef] [PubMed]

13. Clague, M.J.; Urbe, S. Ubiquitin: Same Molecule, Different Degradation Pathways. Cell 2010, 143, $682-685$. [CrossRef] [PubMed] 
14. Kwon, Y.T.; Ciechanover, A.J. The Ubiquitin Code in the Ubiquitin-Proteasome System and Autophagy. Trends Biochem. Sci. 2017, 42, 873-886. [CrossRef] [PubMed]

15. Ciechanover, A.; Kwon, Y.T. Degradation of misfolded proteins in neurodegenerative diseases: Therapeutic targets and strategies. Exp. Mol. Med. 2015, 47, e147. [CrossRef] [PubMed]

16. Clague, M.J.; Urbe, S. Endocytosis: The DUB version. Trends Cell Boil. 2006, 16, 551-559. [CrossRef] [PubMed]

17. Komander, D.; Clague, M.J.; Urbe, S. Breaking the chains: Structure and function of the deubiquitinases. Nat. Rev. Mol. Cell Boil. 2009, 10, 550-563. [CrossRef]

18. Mevissen, T.E.; Komander, D. Mechanisms of Deubiquitinase Specificity and Regulation. Annu. Rev. Biochem. 2017, 86, 159-192. [CrossRef]

19. Bienko, M.; Green, C.; Crosetto, N.; Rudolf, F.; Zapart, G.; Coull, B.; Kannouche, P.; Wider, G.; Peter, M.; Lehmann, A.R.; et al. Ubiquitin-Binding Domains in Y-Family Polymerases Regulate Translesion Synthesis. Science 2005, 310, 1821-1824. [CrossRef]

20. Bienko, M.; Green, C.; Sabbioneda, S.; Crosetto, N.; Matic, I.; Hibbert, R.G.; Begovic, T.; Niimi, A.; Mann, M.; Lehmann, A.R.; et al. Regulation of Translesion Synthesis DNA Polymerase $\eta$ by Monoubiquitination. Mol. Cell 2010, 37, 396-407. [CrossRef]

21. Husnjak, K.; Dikic, I. Ubiquitin-Binding Proteins: Decoders of Ubiquitin-Mediated Cellular Functions. Annu. Rev. Biochem. 2012, 81, 291-322. [CrossRef] [PubMed]

22. Lai, A.; Sisodia, S.S.; Trowbridge, I.S. Characterization of sorting signals in the beta-amyloid precursor protein cytoplasmic domain. J. Boil. Chem. 1995, 270, 3565-3573. [CrossRef]

23. Perez, R.G.; Soriano, S.; Hayes, J.D.; Ostaszewski, B.; Xia, W.; Selkoe, D.J.; Chen, X.; Stokin, G.B.; Koo, E.H. Mutagenesis identifies new signals for beta-amyloid precursor protein endocytosis, turnover, and the generation of secreted fragments, including Abeta42. J. Boil. Chem. 1999, 274, 18851-18856. [CrossRef] [PubMed]

24. Burgos, P.V.; Mardones, G.A.; Rojas, A.L.; DaSilva, L.L.; Prabhu, Y.; Hurley, J.H.; Bonifacino, J.S. Sorting of the Alzheimer's Disease Amyloid Precursor Protein Mediated by the AP-4 Complex. Dev. Cell 2010, 18, 425-436. [CrossRef] [PubMed]

25. Watanabe, T.; Hikichi, Y.; Willuweit, A.; Shintani, Y.; Horiguchi, T. FBL2 Regulates Amyloid Precursor Protein (APP) Metabolism by Promoting Ubiquitination-Dependent APP Degradation and Inhibition of APP Endocytosis. J. Neurosci. 2012, 32, 3352-3365. [CrossRef] [PubMed]

26. El Ayadi, A.; Stieren, E.S.; Barral, J.M.; Boehning, D. Ubiquilin-1 regulates amyloid precursor protein maturation and degradation by stimulating K63-linked polyubiquitination of lysine Proc. Natl. Acad. Sci. USA 2012, 109, 13416-13421. [CrossRef]

27. Morel, E.; Chamoun, Z.; Lasiecka, Z.M.; Chan, R.B.; Williamson, R.L.; Vetanovetz, C.; Dall'Armi, C.; Simoes, S.; Du Jour, K.S.P.; McCabe, B.D.; et al. Phosphatidylinositol-3-phosphate regulates sorting and processing of amyloid precursor protein through the endosomal system. Nat. Commun. 2013, 4, 2250. [CrossRef]

28. Williamson, R.L.; Laulagnier, K.; Miranda, A.M.; Fernandez, M.A.; Wolfe, M.S.; Sadoul, R.; Di Paolo, G. Disruption of amyloid precursor protein ubiquitination selectively increases amyloid $\beta$ (A $\beta$ ) 40 levels via presenilin 2-mediated cleavage. J. Boil. Chem. 2017, 292, 19873-19889. [CrossRef]

29. Cooper, E.M.; Cutcliffe, C.; Kristiansen, T.Z.; Pandey, A.; Pickart, C.M.; Cohen, R.E. K63-specific deubiquitination by two JAMM/MPN+ complexes: BRISC-associated Brcc36 and proteasomal Poh1. EMBO J. 2009, 28, 621-631. [CrossRef]

30. Prabhu, Y.; Burgos, P.V.; Schindler, C.; Farías, G.G.; Magadár, J.G.; Bonifacino, J.S. Adaptor protein 2-mediated endocytosis of the $\beta$-secretase BACE1 is dispensable for amyloid precursor protein processing. Mol. Boil. Cell 2012, 23, 2339-2351. [CrossRef]

31. Bustamante, H.A.; Rivera-Dictter, A.; Cavieres, V.A.; Muñoz, V.C.; González, A.; Lin, Y.; Mardones, G.A.; Burgos, P.V. Turnover of C99 is Controlled by a Crosstalk between ERAD and Ubiquitin-Independent Lysosomal Degradation in Human Neuroglioma Cells. PLoS ONE 2013, 8, e83096. [CrossRef] [PubMed]

32. Cancino, J.; Capalbo, A.; Di Campli, A.; Giannotta, M.; Rizzo, R.; Jung, J.E.; Di Martino, R.; Persico, M.; Heinklein, P.; Sallese, M.; et al. Control Systems of Membrane Transport at the Interface between the Endoplasmic Reticulum and the Golgi. Dev. Cell 2014, 30, 280-294. [CrossRef] [PubMed]

33. Bett, J.S.; Ibrahim, A.F.M.; Garg, A.K.; Rocha, S.; Hay, R. siRNA Screening to Identify Ubiquitin and Ubiquitin-like System Regulators of Biological Pathways in Cultured Mammalian Cells. J. Vis. Exp. 2014. [CrossRef] [PubMed] 
34. Mackay, C.; Carroll, E.; Ibrahim, A.F.; Garg, A.; Inman, G.; Hay, R.; Alpi, A. E3 ubiquitin ligase HOIP attenuates apoptotic cell death induced by cisplatin. Cancer Res. 2014, 74, 2246-2257. [CrossRef] [PubMed]

35. Livak, K.J.; Schmittgen, T.D. Analysis of relative gene expression data using real-time quantitative PCR and the 2(-Delta Delta C(T)) method. Methods 2001, 25, 402-408. [CrossRef] [PubMed]

36. Pfaffl, M.W. A new mathematical model for relative quantification in real-time RT-PCR. Nucleic Acids Res. 2001, 29, 45. [CrossRef]

37. Mlynarczuk-Bialy, I.; Doeppner, T.R.; Golab, J.; Nowis, D.; Wilczyński, G.; Parobczak, K.; Wigand, M.E.; Hajdamowicz, M.; Bialy, L.; Aniolek, O.; et al. Biodistribution and Efficacy Studies of the Proteasome Inhibitor BSc2118 in a Mouse Melanoma Model. Transl. Oncol. 2014, 7, 570-579. [CrossRef]

38. González, A.E.; Muñoz, V.C.; Cavieres, V.A.; Bustamante, H.A.; Cornejo, V.-H.; Januário, Y.C.; González, I.; Hetz, C.; DaSilva, L.L.; Rojas-Fernández, A.; et al. Autophagosomes cooperate in the degradation of intracellular C-terminal fragments of the amyloid precursor protein via the MVB/lysosomal pathway. FASEB J. 2017, 31, 2446-2459. [CrossRef]

39. Moffat, J.; Reiling, J.H.; Sabatini, D.M. Off-target effects associated with long dsRNAs in Drosophila RNAi screens. Trends Pharmacol. Sci. 2007, 28, 149-151. [CrossRef]

40. Verma, R.; Aravind, L.; Oania, R.; McDonald, W.H.; Yates, J.R.; Koonin, E.V.; Deshaies, R. Role of Rpn11 Metalloprotease in Deubiquitination and Degradation by the 26S Proteasome. Science 2002, 298, 611-615. [CrossRef]

41. Yao, T.; Cohen, R.E. A cryptic protease couples deubiquitination and degradation by the proteasome. Nature 2002, 419, 403-407. [CrossRef] [PubMed]

42. Li, J.; Yakushi, T.; Parlati, F.; Mackinnon, A.L.; Perez, C.; Ma, Y.; Carter, K.P.; Colayco, S.; Magnuson, G.; Brown, B.; et al. Capzimin is a potent and specific inhibitor of proteasome isopeptidase RpnNat. Chem. Biol. 2017, 13, 486-493.

43. Tsubuki, S.; Saito, Y.; Tomioka, M.; Ito, H.; Kawashima, S. Differential Inhibition of Calpain and Proteasome Activities by Peptidyl Aldehydes of Di-Leucine and Tri-Leucine. J. Biochem. 1996, 119, 572-576. [CrossRef] [PubMed]

44. Kisselev, A.F.; Goldberg, A.L. Proteasome inhibitors: From research tools to drug candidates. Chem. Boil. 2001, 8, 739-758. [CrossRef]

45. Wieland, F.T.; Gleason, M.L.; Serafini, T.A.; Rothman, J.E. The rate of bulk flow from the endoplasmic reticulum to the cell surface. Cell 1987, 50, 289-300. [CrossRef]

46. Martínez-Menárguez, J.A.; Geuze, H.J.; Slot, J.W.; Klumperman, J. Vesicular Tubular Clusters between the ER and Golgi Mediate Concentration of Soluble Secretory Proteins by Exclusion from COPI-Coated Vesicles. Cell 1999, 98, 81-90. [CrossRef]

47. Klumperman, J. Transport between ER and Golgi. Curr. Opin. Cell Boil. 2000, 12, 445-449. [CrossRef]

48. Thor, F.; Gautschi, M.; Geiger, R.; Helenius, A. Bulk Flow Revisited: Transport of a Soluble Protein in the Secretory Pathway. Traffic 2009, 10, 1819-1830. [CrossRef]

49. Tenorio, M.J.; Luchsinger, C.; Mardones, G.A. Protein Kinase A Activity Is Necessary for Fission and Fusion of Golgi to Endoplasmic Reticulum Retrograde Tubules. PLoS ONE 2015, 10, e0135260. [CrossRef]

50. Hsu, V.W.; Shah, N.; Klausner, R.D. A brefeldin A-like phenotype is induced by the overexpression of a human ERD-2-like protein, ELP-1. Cell 1992, 69, 625-635. [CrossRef]

51. Cole, N.B.; Ellenberg, J.; Song, J.; DiEuliis, D.; Lippincott-Schwartz, J. Retrograde Transport of Golgi-localized Proteins to the ER. J. Cell Boil. 1998, 140, 1-15. [CrossRef] [PubMed]

52. Lewis, M.J.; Rayner, J.C.; Pelham, H.R.B. A novel SNARE complex implicated in vesicle fusion with the endoplasmic reticulum. EMBO J. 1997, 16, 3017-3024. [CrossRef] [PubMed]

53. He, S.; Ni, D.; Ma, B.; Lee, J.-H.; Zhang, T.; Ghozalli, I.; Pirooz, S.D.; Zhao, Z.; Bharatham, N.; Li, B.; et al. PtdIns(3)P-bound UVRAG coordinates Golgi-ER retrograde and Atg9 transport by differential interactions with the ER tether and the beclin 1 complex. Nature 2013, 15, 1206-1219. [CrossRef] [PubMed]

54. Lemus, L.; Ribas, J.L.; Sikorska, N.; Goder, V. An ER-Localized SNARE Protein Is Exported in Specific COPII Vesicles for Autophagosome Biogenesis. Cell Rep. 2016, 14, 1710-1722. [CrossRef] [PubMed]

55. Chen, Q.; Xiao, Y.; Chai, P.; Zheng, P.; Teng, J.; Chen, J. ATL3 Is a Tubular ER-Phagy Receptor for GABARAP-Mediated Selective Autophagy. Curr. Boil. 2019, 29, 846-855.e6. [CrossRef]

56. Hao, R.; Nanduri, P.; Rao, Y.; Panichelli, R.S.; Ito, A.; Yoshida, M.; Yao, T.-P. Proteasomes activate aggresome disassembly and clearance by producing unanchored ubiquitin chains. Mol. Cell 2013, 51, 819-828. [CrossRef] 
57. Nanduri, P.; Hao, R.; Fitzpatrick, T.; Yao, T.-P. Chaperone-mediated 26S Proteasome Remodeling Facilitates Free K63 Ubiquitin Chain Production and Aggresome Clearance*. J. Boil. Chem. 2015, 290, 9455-9464. [CrossRef]

58. Kabeya, Y.; Mizushima, N.; Ueno, T.; Yamamoto, A.; Kirisako, T.; Noda, T.; Kominami, E.; Ohsumi, Y.; Yoshimori, T. LC3, a mammalian homologue of yeast Apg8p, is localized in autophagosome membranes after processing. EMBO J. 2000, 19, 5720-5728. [CrossRef]

59. Munafó, D.B.; Colombo, M.I. A novel assay to study autophagy: Regulation of autophagosome vacuole size by amino acid deprivation. J. Cell Sci. 2001, 114, 3619-3629.

60. Thoreen, C.C.; Kang, S.A.; Chang, J.W.; Liu, Q.; Zhang, J.; Gao, Y.; Reichling, L.J.; Sim, T.; Sabatini, D.M.; Gray, N.S. An ATP-competitive mammalian target of rapamycin inhibitor reveals rapamycin-resistant functions of mTORCJ. Biol. Chem. 2009, 284, 8023-8032. [CrossRef]

61. Winslow, A.R.; Chen, C.-W.; Corrochano, S.; Acevedo-Arozena, A.; Gordon, D.E.; A Peden, A.; Lichtenberg, M.; Menzies, F.M.; Ravikumar, B.; Imarisio, S.; et al. $\alpha$-Synuclein impairs macroautophagy: Implications for Parkinson's disease. J. Cell Boil. 2010, 190, 1023-1037. [CrossRef] [PubMed]

62. Webster, C.P.; Smith, E.F.; Bauer, C.S.; Moller, A.; Hautbergue, G.; Ferraiuolo, L.; Myszczynska, M.; Higginbottom, A.; Walsh, M.J.; Whitworth, A.J.; et al. The C9orf72 protein interacts with Rab1a and the ULK 1 complex to regulate initiation of autophagy. EMBO J. 2016, 35, 1656-1676. [CrossRef] [PubMed]

63. Orsi, A.; Razi, M.; Dooley, H.C.; Robinson, D.; Weston, A.; Collinson, L.M.; Tooze, S.A. Dynamic and transient interactions of Atg9 with autophagosomes, but not membrane integration, are required for autophagy. Mol. Boil. Cell 2012, 23, 1860-1873. [CrossRef] [PubMed]

64. Kishi-Itakura, C.; Koyama-Honda, I.; Itakura, E.; Mizushima, N. Ultrastructural analysis of autophagosome organization using mammalian autophagy-deficient cells. J. Cell Sci. 2014, 127, 4984. [CrossRef]

65. Karanasios, E.; Walker, S.; Okkenhaug, H.; Manifava, M.; Hummel, E.; Zimmermann, H.; Ahmed, Q.; Domart, M.-C.; Collinson, L.M.; Ktistakis, N.T. Autophagy initiation by ULK complex assembly on ER tubulovesicular regions marked by ATG9 vesicles. Nat. Commun. 2016, 7, 12420. [CrossRef]

66. Tapia, D.; Jiménez, T.; Zamora, C.; Espinoza, J.; Rizzo, R.; González-Cárdenas, A.; Fuentes, D.; Hernández, S.; Cavieres, V.A.; Soza, A.; et al. KDEL receptor regulates secretion by lysosome relocation- and autophagy-dependent modulation of lipid-droplet turnover. Nat. Commun. 2019, 10, 735. [CrossRef]

67. Iwata, A.; Riley, B.E.; Johnston, J.; Kopito, R.R. HDAC6 and Microtubules Are Required for Autophagic Degradation of Aggregated Huntingtin. J. Boil. Chem. 2005, 280, 40282-40292. [CrossRef]

68. Ding, W.-X.; Ni, H.-M.; Gao, W.; Yoshimori, T.; Stolz, N.B.; Ron, D.; Yin, X.-M. Linking of Autophagy to Ubiquitin-Proteasome System Is Important for the Regulation of Endoplasmic Reticulum Stress and Cell Viability. Am. J. Pathol. 2007, 171, 513-524. [CrossRef]

69. Lan, D.; Wang, W.; Zhuang, J.; Zhao, Z. Proteasome inhibitor-induced autophagy in PC12 cells overexpressing A53T mutant $\alpha$-synuclein. Mol. Med. Rep. 2014, 11, 1655-1660. [CrossRef]

70. Peng, H.; Yang, J.; Li, G.; You, Q.; Han, W.; Li, T.; Gao, D.; Xie, X.; Lee, B.-H.; Du, J.; et al. Ubiquitylation of p62/sequestosome1 activates its autophagy receptor function and controls selective autophagy upon ubiquitin stress. Cell Res. 2017, 27, 657-674. [CrossRef]

71. Milani, M.; Rzymski, T.; Mellor, H.R.; Pike, L.; Bottini, A.; Generali, D.; Harris, A.L. The Role of ATF4 Stabilization and Autophagy in Resistance of Breast Cancer Cells Treated with Bortezomib. Cancer Res. 2009, 69, 4415-4423. [CrossRef]

72. Albornoz, N.; Bustamante, H.; Soza, A.; Burgos, P. Cellular Responses to Proteasome Inhibition: Molecular Mechanisms and Beyond. Int. J. Mol. Sci. 2019, 20, 3379. [CrossRef]

73. Zhou, F.; Van Laar, T.; Huang, H.; Zhang, L. APP and APLP1 are degraded through autophagy in response to proteasome inhibition in neuronal cells. Protein Cell 2011, 2, 377-383. [CrossRef]

74. Swaminathan, G.; Zhu, W.; Plowey, E.D. BECN1/Beclin 1 sorts cell-surface APP/amyloid $\beta$ precursor protein for lysosomal degradation. Autophagy 2016, 12, 2404-2419. [CrossRef] [PubMed]

75. Wang, B.-J.; Her, G.M.; Hu, M.-K.; Chen, Y.-W.; Tung, Y.-T.; Wu, P.-Y.; Hsu, W.-M.; Lee, H.; Jin, L.-W.; Hwang, S.-P.L.; et al. ErbB2 regulates autophagic flux to modulate the proteostasis of APP-CTFs in Alzheimer's disease. Proc. Natl. Acad. Sci. USA 2017, 114, E3129-E3138. [CrossRef]

76. Yang, C.; Cai, C.-Z.; Song, J.; Tan, J.-Q.; Durairajan, S.S.K.; Iyaswamy, A.; Wu, M.-Y.; Chen, L.-L.; Yue, Z.; Li, M.; et al. NRBF2 is involved in the autophagic degradation process of APP-CTFs in Alzheimer disease models. Autophagy 2017, 13, 2028-2040. [CrossRef] [PubMed] 
77. Zhang, J.; Liu, J.; Norris, A.; Grant, B.D.; Wang, X. A novel requirement for ubiquitin-conjugating enzyme UBC-13 in retrograde recycling of MIG-14/Wntless and Wnt signaling. Mol. Biol. Cell 2018, 29, 2098-2112. [CrossRef] [PubMed]

78. Deng, L.; Jiang, C.; Chen, L.; Jin, J.; Wei, J.; Zhao, L.; Chen, M.; Pan, W.; Xu, Y.; Chu, H.; et al. The Ubiquitination of RagA GTPase by RNF152 Negatively Regulates mTORC1 Activation. Mol. Cell 2015, 58, 804-818. [CrossRef] [PubMed]

79. Ji, C.H.; Kim, H.Y.; Heo, A.J.; Lee, S.H.; Lee, M.J.; Bin Kim, S.; SrinivasRao, G.; Mun, S.R.; Cha-Molstad, H.; Ciechanover, A.; et al. The N-Degron Pathway Mediates ER-phagy. Mol. Cell 2019, 75, 1058-1072.e9. [CrossRef]

80. Kawaguchi, Y.; Kovacs, J.J.; McLaurin, A.; Vance, J.; Ito, A.; Yao, T.-P. The Deacetylase HDAC6 Regulates Aggresome Formation and Cell Viability in Response to Misfolded Protein Stress. Cell 2003, 115, 727-738. [CrossRef]

81. Cohen, M.M.; Stutz, F.; Dargemont, C. Deubiquitination, a New Player in Golgi to Endoplasmic Reticulum Retrograde Transport. J. Boil. Chem. 2003, 278, 51989-51992. [CrossRef] [PubMed]

82. Millard, S.; Wood, S. Riding the DUBway: Regulation of protein trafficking by deubiquitylating enzymes. J. Cell Boil. 2006, 173, 463-468. [CrossRef]

83. Cohen, M.M.; Stutz, F.; Belgareh, N.; Haguenauer-Tsapis, R.; Dargemont, C. Ubp3 requires a cofactor, Bre5, to specifically de-ubiquitinate the COPII protein, Sec23. Nature 2003, 5, 661-667. [CrossRef] [PubMed]

84. Bettayeb, K.; Chang, J.C.; Luo, W.; Aryal, S.; Varotsis, D.; Randolph, L.; Netzer, W.J.; Greengard, P.; Flajolet, M. $\delta$-COP modulates A $\beta$ peptide formation via retrograde trafficking of APP. Proc. Natl. Acad. Sci. USA 2016, 113, 5412-5417. [CrossRef] [PubMed]

85. He, S.; O'Connell, D.; Zhang, X.; Yang, Y.; Liang, C. The intersection of Golgi-ER retrograde and autophagic trafficking. Autophagy 2013, 10, 180-181. [CrossRef]

86. Rinaldi, L.; Donne, R.D.; Catalanotti, B.; Torres-Quesada, O.; Enzler, F.; Moraca, F.; Nisticò, R.; Chiuso, F.; Piccinin, S.; Bachmann, V.; et al. Feedback inhibition of cAMP effector signaling by a chaperone-assisted ubiquitin system. Nat. Commun. 2019, 10, 2572. [CrossRef]

87. Feng, X.; Jia, Y.; Zhang, Y.; Ma, F.; Zhu, Y.; Hong, X.; Zhou, Q.; He, R.; Zhang, H.; Jin, J.; et al. Ubiquitination of UVRAG by SMURF1 promotes autophagosome maturation and inhibits hepatocellular carcinoma growth. Autophagy 2019, 15, 1130-1149. [CrossRef]

88. Saitoh, T.; Fujita, N.; Hayashi, T.; Takahara, K.; Satoh, T.; Lee, H.; Matsunaga, K.; Kageyama, S.; Omori, H.; Noda, T.; et al. Atg9a controls dsDNA-driven dynamic translocation of STING and the innate immune response. Proc. Natl. Acad. Sci. USA 2009, 106, 20842-20846. [CrossRef]

89. Mattera, R.; Park, S.Y.; De Pace, R.; Guardia, C.M.; Bonifacino, J.S. AP-4 mediates export of ATG9A from the trans-Golgi network to promote autophagosome formation. Proc. Natl. Acad. Sci. USA 2017, 114, E10697-E10706. [CrossRef]

90. Song, Y.; Li, S.; Ray, A.; Das, D.S.; Qi, J.; Samur, M.K.; Tai, Y.-T.; Munshi, N.; Carrasco, R.D.; Chauhan, D.; et al. Blockade of deubiquitylating enzyme Rpn11 triggers apoptosis in multiple myeloma cells and overcomes bortezomib resistance. Oncogene 2017, 36, 5631-5638. [CrossRef]

91. Wang, C.-H.; Lu, S.-X.; Liu, L.-L.; Li, Y.; Yang, X.; He, Y.-F.; Chen, S.-L.; Cai, S.; Wang, H.; Yun, J. POH1 Knockdown Induces Cancer Cell Apoptosis via p53 and Bim. Neoplasia 2018, 20, 411-424. [CrossRef] [PubMed]

92. Deshaies, R. Proteotoxic crisis, the ubiquitin-proteasome system, and cancer therapy. BMC Boil. 2014, 12, 94. [CrossRef] [PubMed]

(C) 2020 by the authors. Licensee MDPI, Basel, Switzerland. This article is an open access article distributed under the terms and conditions of the Creative Commons Attribution (CC BY) license (http://creativecommons.org/licenses/by/4.0/). 